\title{
Central Compensation in Auditory Brainstem after Damaging Noise Exposure
}

\author{
(D) Katrina M. Schrode, ${ }^{1}$ (D) Michael A. Muniak, ${ }^{2,3}$ Ye-Hyun Kim, ${ }^{1}$ and Amanda M. Lauer ${ }^{1}$
}

https://doi.org/10.1523/ENEURO.0250-18.2018

${ }^{1}$ Department of Otolaryngology, Johns Hopkins School of Medicine, Baltimore, MD 21205, ${ }^{2}$ Hearing Research, Garvan Institute of Medical Research, Sydney, NSW 2010, Australia, ${ }^{3}$ St Vincent's Clinical School, UNSW Sydney, Sydney, NSW 2052, Australia

\begin{abstract}
Noise exposure is one of the most common causes of hearing loss and peripheral damage to the auditory system. A growing literature suggests that the auditory system can compensate for peripheral loss through increased central neural activity. The current study sought to investigate the link between noise exposure, increases in central gain, synaptic reorganization, and auditory function. All axons of the auditory nerve project to the cochlear nucleus, making it a requisite nucleus for sound detection. As the first synapse in the central auditory system, the cochlear nucleus is well positioned to respond plastically to loss of peripheral input. To investigate noise-induced compensation in the central auditory system, we measured auditory brainstem responses (ABRs) and auditory perception and collected tissue from mice exposed to broadband noise. Noise-exposed mice showed elevated ABR thresholds, reduced ABR wave 1 amplitudes, and spiral ganglion neuron loss. Despite peripheral damage, noise-exposed mice were hyperreactive to loud sounds and showed nearly normal behavioral sound detection thresholds. Ratios of late ABR peaks (2-4) relative to the first ABR peak indicated that brainstem pathways were hyperactive in noise-exposed mice, while anatomical analysis indicated there was an imbalance between expression of excitatory and inhibitory proteins in the ventral cochlear nucleus. The results of the current study suggest that a reorganization of excitation and inhibition in the ventral cochlear nucleus may drive hyperactivity in the central auditory system. This increase in central gain can compensate for peripheral loss to restore some aspects of auditory function.
\end{abstract}

Key words: Auditory; brainstem; compensation; hyperactivity

\section{Significance Statement}

Noise exposure can cause significant damage to the peripheral auditory system. Previous work has shown that the dorsal cochlear nucleus, inferior colliculus, auditory thalamus, and auditory cortex become hyperactive following damage to the peripheral auditory system, which may compensate for decreased sensory input. Here we show that after noise exposure, hyperactivity develops in the auditory brainstem as a result of reorganization of excitation and inhibition in the ventral cochlear nucleus. The compensatory plasticity observed at this early stage of the primary auditory pathway may contribute to the hyperactivity reported at later stages. Further, we show that this hyperactivity can compensate for reduced sensory input to partially restore some aspects of auditory function.

\section{Introduction}

Deafness can have detrimental consequences on synapse morphology and function of the central auditory system (Gravel and Ruben, 1996; Shepherd et al., 2006;

Received June 27, 2018; accepted July 19, 2018; First published July 26, 2018.

The authors report no competing financial interests.
Muniak et al., 2013a). Substantial gaps remain in our knowledge of the central effects of acquired hearing loss. The goal of the present study was to link central changes

Author contributions: K.M.S. and A.M.L. designed research; K.M.S. and Y.-H.K. performed research; K.M.S., M.A.M., Y.-H.K., and A.M.L. analyzed data; K.M.S., M.A.M., Y.-H.K., and A.M.L. wrote the paper. 
Table 1. Numbers of CBA/CaJ mice of used for each procedure

\begin{tabular}{lllll}
\hline Procedure & Total mice & Sham mice $(\mathrm{F} ; \mathrm{M})$ & Noise mice $(\mathrm{F} ; \mathrm{M})$ & Age \\
ABR & 82 & $41(21 ; 20)$ & $41(22 ; 19)$ & 10 weeks \\
GAD65 labeling & 12 & $7(3 ; 4)$ & $5(2 ; 3)$ & $2.5-5$ months \\
VGLUT1 labeling & 12 & $6(3 ; 3)$ & $6(3 ; 3)$ & $2.5-5$ months \\
SGN counts & 18 & $11(5 ; 6)$ & $7(4 ; 3)$ & $2.5-5$ months \\
CTBP2 labeling & 8 & $3(1 ; 2)$ & $5(1 ; 4)$ & $2.5-5$ months \\
ASR & 21 & $10(6 ; 4)$ & $11(4 ; 7)$ & $2.5-5$ months \\
CLS & 14 & $14(7 ; 7)$ & $5(2 ; 3)$ & $2.5-5$ months \\
\hline
\end{tabular}

in neural reorganization with changes in brainstem physiology and perception in an animal model of bilateral noise-induced hearing loss.

One of the most common causes of acquired hearing loss is damaging noise exposure. Many studies have detailed the consequences of noise exposure on the anatomy, physiology, and function of the inner ear (Schmiedt, 1984; Saunders et al., 1985; Henderson et al., 2006). Noise exposure can damage hair cells, supporting cells, auditory afferent dendrites, spiral ganglion neurons (SGNs), and the stria vascularis, all resulting in reduced afferent input to the central auditory system. A growing literature suggests that increased neural activity develops in central auditory structures including the dorsal cochlear nucleus (DCN), inferior colliculus, thalamus, and auditory cortex following sound exposure (Salvi et al., 2000; Seki and Eggermont, 2003; Ma et al., 2006; Brozoski et al., 2007; Kaltenbach, 2007; Bauer et al., 2008; Izquierdo et al., 2008; Shore et al., 2008; Longenecker and Galazyuk, 2011; Middleton et al., 2011; Vogler et al., 2011; Barker et al., 2012; Dehmel et al., 2012b; Gold and Bajo, 2014; Kalappa et al., 2014). The predominant hypothesis is that central hyperactivity acts as a gain control to compensate for the reduced afferent input from the ear (Potashner et al., 1997; Kaltenbach et al., 2000; Milbrandt et al., 2000; Salvi et al., 2000; Brozoski et al., 2002; Schaette and McAlpine, 2011).

There is some evidence that both spontaneous (Vogler et al., 2011; Robertson et al., 2013) and evoked (Boettcher and Salvi, 1993; Cai et al., 2009) neural activity are enhanced in the ventral cochlear nucleus (VCN) following noise exposure. Other studies have found evidence for hyperactivity in the brainstem using auditory brainstem responses (ABRs; e.g. Hickox and Liberman, 2014; Lowe and Walton, 2015; Möhrle et al., 2016). The first peak of the ABR, generated by the auditory nerve, is reduced after

Supported by NIH grants DC000023, DC005211, DC016641, NHMRC grant 1080652, a gift from Liquin Zeng, and the David M. Rubenstein Fund for Hearing Research. The content is solely the responsibility of the authors and does not necessarily represent the official views of the funding agencies.

Acknowledgments: We thank Brian McGuire, Hamad Javaid, James Engel, and Aikeen Jones for assistance with data collection.

Correspondence should be addressed to Katrina M. Schrode, Department of Otolaryngology, Johns Hopkins School of Medicine, Baltimore, MD, 21205. E-mail: kschrod1@jhmi.edu

https://doi.org/10.1523/ENEURO.0250-18.2018

Copyright $\odot 2018$ Schrode et al.

This is an open-access article distributed under the terms of the Creative Commons Attribution 4.0 International license, which permits unrestricted use, distribution and reproduction in any medium provided that the original work is properly attributed. noise exposure. Later ABR waves (2-5 in animals, III to V in humans) are primarily generated by bushy cells of the VCN and bushy cell-driven pathways (Melcher and Kiang, 1996). Following sound exposure, these central waves, or their amplitudes relative to wave 1, are increased, indicating hyperactivity (Hickox and Liberman, 2014; Lowe and Walton, 2015; Möhrle et al., 2016).

Hyperactivity observed in the later ABR waves presumably reflects an imbalance of excitation and inhibition, contributing to relatively larger neural responses in the VCN and upstream auditory brainstem nuclei compared to the auditory nerve. This imbalance could be due to increased activity in excitatory synapses and/or reduced inhibitory activity. Previous work has found evidence for both. Glutamatergic release and receptor gene expression in the VCN show long-term increases after unilateral exposure (Muly et al., 2004; Dong et al., 2010). On the other hand, inhibitory GABAergic and glycinergic receptor genes are downregulated shortly after unilateral sound exposure but upregulated over a longer time scale (Dong et al., 2010). These changes have not been investigated for bilateral noise exposures.

In the present study, we investigated the perceptual, physiologic, and anatomic consequences of bilateral noise exposure in mice. We used a combination of ABRs and immunohistochemistry to determine if the VCN exhibits sound-evoked hyperactivity following sound exposure and measured tone detection and acoustic startle reflex (ASR) to test whether this hyperactivity could functionally compensate for reduced afferent input to support detection of and reactivity to sounds. Compared to shamexposed mice, noise-exposed mice exhibited increased hyperactivity in the brainstem and an imbalance between excitatory and inhibitory presynaptic protein expression, but showed only small elevations in perceptual thresholds and enhanced reactivity to sound. Our results suggest that central hyperactivity can compensate for decreased sensory input to restore some auditory function.

\section{Materials and Methods}

\section{Subjects}

Subjects were young adult male and female CBA/CaJ mice bred in our colony from founders originally obtained from Jackson Laboratory (stock \#000654). The numbers used in each procedure are detailed in Table 1. Animals were bred and housed in a quiet, low-traffic room to minimize extraneous noise exposure (Lauer et al., 2009). All procedures were approved by the Johns Hopkins University Animal Care and Use Committee and performed in 
accordance with the Guide for the Care and Use of Laboratory Animals.

\section{Noise exposures}

Noise exposures and sham exposures were performed on 6-week-old mice. Home cages were placed in the room containing the apparatus $30 \mathrm{~min}$ before commencement of exposure to allow subjects time to acclimate to the new surroundings. For both noise and sham exposure conditions, awake mice were selected at random and placed in a small wire cage mounted inside a small soundattenuating booth [Industrial Acoustic Company (IAC)] below two speakers (TW57; Pyramid Audio). Broadband noise was generated using Matlab (MathWorks) and broadcast via a processor [RX6; Tucker-Davis Technologies (TDT)] and an amplifier (CH1; Crown Harman). We calibrated the noise to $100 \mathrm{~dB} \mathrm{SPL}$ at the location of the cage before exposure using a half-inch free-field microphone and Z-weighting (SoundTrack LxT, Larson Davis). Mice were exposed to broadband noise $(2-50 \mathrm{kHz})$ for 2 hours while the cage was gradually rotated within the sound field. Animals undergoing sham exposure conditions (controls) were placed in the rotating cage inside the sound booth for 2 hours, but no noise was presented. The same experimenter, a young adult female, performed all exposures. Exposures occurred during the hours of 8:00 am and 6:00 pm with the booth lights turned on so as not to disrupt the mice's circadian cycle.

\section{Auditory brainstem response}

We recorded ABRs 1 month after exposure to measure auditory sensitivity and determine if the auditory brainstem exhibited hyperactivity. Procedures were similar to those described by McGuire et al. (2015) and Lauer (2017). Mice were anesthetized with $100 \mathrm{mg} / \mathrm{kg}$ ketamine and $20 \mathrm{mg} / \mathrm{kg}$ xylazine and placed on a heating pad inside a small sound-attenuating chamber (IAC) lined with Sonex acoustic foam to reduce acoustic reflections. Mice were placed in front of a speaker (FT28D; Fostex) with the speaker positioned $30 \mathrm{~cm}$ from the vertex of the skull. We monitored body temperature via a rectal probe and maintained it at $36 \pm 1{ }^{\circ} \mathrm{C}$. Subcutaneous platinum needle electrodes were placed over the left bulla and at the vertex of the skull, and a ground electrode was inserted into the leg muscle. The electrodes were attached to a preamplifier leading to an amplifier (ISO-80; World Precision Instruments).

Stimulus generation, presentation, and response acquisition were controlled using custom Matlab-based software, a TDT RX6, and a PC. Stimuli consisted of clicks (0.1-ms square wave pulse of alternating polarity) and 5 -ms tones at frequencies of $6,8,12,16,24$, and $32 \mathrm{kHz}$ (0.5-ms onset/offset), generated with a sampling frequency of $195 \mathrm{kHz}$, and presented at a rate of $20 / \mathrm{s}$. We calibrated stimuli using a quarter-inch free-field microphone (type 4939; Brüel and Kjær) placed at the location of the mouse's head and custom Matlab-based software. Responses were sampled at $9.5 \mathrm{kHz}$, bandpass filtered from 300 to $3000 \mathrm{kHz}$, and averaged over 300 stimulus repetitions. We tested clicks first, to verify electrode placement and the presence of a clearly observable re- sponse, and then tested tone stimuli in random order. We presented a given stimulus at descending levels starting at 85-105 dB (depending on frequency) until a threshold was reached. Threshold was defined as the sound level at which the ABR peak-to-peak (any peak) amplitude was two standard deviations above the average baseline amplitude during the period of the recording when no sound stimulus was present. The amplitudes of the ABR and baseline were calculated within 8-ms windows beginning 2 ms after stimulus onset and $\sim 20 \mathrm{~ms}$ after onset, respectively. We manually measured amplitudes of peaks 1 through 4 offline using custom software. Peak 5 was not reliably detected in our recordings, consistent with reports from others (Zheng et al., 1999), so we did not measure or analyze it further. Testing lasted $\sim 40-60 \mathrm{~min}$; mice were returned to their home cages following testing and monitored until recovery.

\section{Acoustic startle reflex}

We used ASR to evaluate whether functional reactivity to sound was altered in noise-exposed mice. ASR was performed in a small sound-attenuating chamber (IAC) lined with Sonex acoustic foam to reduce acoustic reflections. Mice were placed inside a small, custom-made, sound-permeable, half-cylindrical-shaped testing cage. The testing cage was mounted onto a platform containing a piezoelectric sensor that transduced the animal's movement into voltage signals that were then amplified using a custom-built amplifier.

All ASR test parameters, stimuli, and recordings were controlled with custom Matlab software. Startle stimuli were 20-ms broadband noise bursts of varying stimulus intensity $(70,80,90,100$, and $105 \mathrm{~dB}$ SPL). Stimuli were generated via a processor (RP2.1; TDT), attenuated (PA5; TDT), amplified (D75A; Crown), and delivered through a speaker (Super Tweeter; Radioshack) placed $10 \mathrm{~cm}$ from the testing cage. The speaker was calibrated with a sound level meter (SoundTrack LxT; Larson Davis) in the approximate location of the animal's head before testing.

Animals were acclimated to the testing cage and sound chamber for $5 \mathrm{~min}$ before the start of testing. Each session consisted of 10 trials at each intensity (50 total) presented in pseudo-random order. Trials were separated by a randomized intertrial interval ranging from 5 to $15 \mathrm{~s}$. The animal's ambient movement was automatically monitored by the testing program at the start of each trial. When the animal was still for a period of $5 \mathrm{~s}$, the startle stimulus was presented. Measurements during the 5-s "quiet movement" period served as a baseline for the animal. For each trial, the animal's startle response output signals were amplified, digitized, and recorded (RP 2.1; TDT) for $100 \mathrm{~ms}$ following the startle stimulus onset. Sessions lasted for 20-25 min. At the end of testing, animals were returned to their home cage. All testing was conducted between the hours of 10:00 am and 4:00 pm by the same experimenter, an adult female.

\section{Tone detection}

We trained mice using operant conditioning to assess how well noise-exposed mice were able to consciously perceive sounds. Mice were trained to detect tones in a 
quiet background using a conditioned lick suppression (CLS) paradigm (Heffner et al., 2006; Lauer et al., 2011). Because it takes mice several weeks to become proficient at CLS, we began testing within a week after sham or noise exposure. Once mice performed well in the basic task (usually after 3-4 weeks), we began measuring thresholds. During testing, mice were water restricted, but allowed unlimited access to food. On any days they were not tested, we provided mice with supplemental hydrating gel.

Testing took place in a sound-attenuating chamber (IAC) lined in Sonex foam. A mouse was placed in a small wire mesh cage containing a lick spout fed via a syringe pump delivery system. Licking was detected through voltage changes induced when the mouse made contact with the spout. A moist sponge was placed against the bottom of the cage to assist with charge transfer. All testing was controlled by a custom program in Matlab operating a multichannel processor (RX8; TDT). Sounds were produced at a sampling rate of $100 \mathrm{kHz}$ (RX8; TDT) and delivered through an amplifier (SA8; TDT) driving a loudspeaker (Vifa) placed 1 meter from the spout. Before testing, we calibrated tone stimuli using a sound level meter with the tip of the microphone placed at the approximate position of the mouse's head (Z-weighting; SoundTrack LxT; Larson Davis).

Mice initiated trials by licking the spout. On warning trials, after a random waiting period of between 2 and $5 \mathrm{~s}$, two $240-m s$ tones separated by a $240-m s$ silent interval were played from the speaker. A mild shock was presented through the spout $40 \mathrm{~ms}$ after sound offset, and mice learned to withdraw from the spout to avoid the shock. Warning trials were presented with a $\sim 25 \%$ probability. During safe trials, no tones were presented, and the animal continued licking to receive juice. Licking was monitored for 720 ms before and after the acoustic stimulus in warning trials and during the equivalent time period for safe trials. For analysis, the relevant time period was split into 35 20-ms "pre" bins and 35 20-ms "post" bins, and we counted the number of bins containing licks. All mice exhibited consistent licking behavior, with licks in at least 20 pre-stimulus bins and no evidence of suppression on safe trials (less than a 10\% difference between number of pre- and post-stimulus bins). We considered the mouse to have responded (i.e., suppressed licking) whenever the post-stimulus bin count was less than or equal to the determined criterion. A response on a safe trial was counted as a false alarm, while a response on a warning trial was counted as a hit. The subject's criterion was calculated such that the false alarm rate was near $16 \%$. Hits and false alarm rates were used to calculate a $d^{\prime}$ for each trial type.

In each testing session, we tested mice with tones of one frequency, at levels in 10-dB intervals using the method of constant stimuli and presented in a random order. The range of levels was adjusted to include one level below threshold. Threshold was defined as the level yielding a d' of 1.0. Given the enforced false alarm rate of $16 \%$, this $d^{\prime}$ reflects a hit rate of $\sim 50 \%$. Mice were allowed to perform trials until they reached satiety, usually
45-60 min, then were returned to their home cages. We measured thresholds for tones of 8,12 , and $16 \mathrm{kHz}$. Mice were tested with each frequency until the calculated threshold differed by $<5 \mathrm{~dB}$ for at least three sessions. Final thresholds are reported as the average of the last 3-4 sessions and include at least 20 warning trials at each sound level.

\section{Spiral ganglion counts}

We counted spiral ganglion neurons in the cochleae of our mice to assess the amount of peripheral damage induced by the noise exposure. Cochleae were embedded in Araldite, following methods similar to Hequembourg and Liberman (2001). Mice were deeply anesthetized with a 0.3-0.5 $\mathrm{mg} / \mathrm{g}$ dose of sodium pentobarbital (i.p.), transcardially perfused with $60 \mathrm{ml}$ of a $4 \%$ paraformaldehyde fixative solution, and decapitated. Following transcardial perfusion, we reperfused the cochleae with $4 \%$ paraformaldehyde through the round and oval windows and postfixed overnight. Cochleae were then removed from the skull and decalcified in 1\% EDTA in phosphate buffer for several days. After a series of progressive dehydrations, cochleae were infiltrated with a solution of Araldite 502 (Electron Microscopy Services) and cured in an oven at $60^{\circ} \mathrm{C}$. Cochleae were sectioned parallel to the modiolus at $30 \mu \mathrm{m}$ and stained with 1\% toluidine blue (Fisher Scientific).

We estimated the number of spiral ganglion neurons following stereology procedures described by Schettino and Lauer (2013). We used the Optical Fractionator Probe in Stereo Investigator (SI) software (MBF Bioscience). The region of interest, Rosenthal's canal, was visualized at $40 \times$ magnification and traced. The SI software placed a sampling grid $(40 \times 40 \mu \mathrm{m})$ at random locations over the region of interest. At each counting location, an observer who was blind to the hearing status of the subject counted the number of spiral ganglion neurons within the grid, refocusing as needed to visualize all neurons and measure the total depth of the tissue. The observer continued through all sections that contained Rosenthal's canal, counting neurons in every third section. When counting was complete, the software estimated the total number of neurons.

\section{Inner ear immunohistochemistry}

To further evaluate the status of the cochlea, we quantified ribbon synapses on inner hair cells and number of inner and outer hair cells in cochlear whole-mount preparations. Cochleae were extracted after transcardial perfusion and fixed for an additional hour, after which they were decalcified in 1\% EDTA. We then dissected the organ of Corti into 5-6 flat turns following methods described by Eaton Peabody Laboratories (https://www.masseyeandear.org/research/ otolaryngology/investigators/laboratories/eaton-peabodylaboratories/epl-histology-resources/cochlear-dissectionsummary). Cochlear pieces were placed in a blocking buffer of $5 \%$ normal goat serum, $10 \%$ bovine serum albumin, and $0.5 \%$ Triton X-100 (Electron Microscopy Services) for $1 \mathrm{~h}$. They were then incubated overnight at $4{ }^{\circ} \mathrm{C}$ in mouse monoclonal anti-CTBP2 (1:200, BD Biosciences, cat\# 612044, RRID:AB_399431), rabbit polyclonal anti-myosin 6 (1:500, 
Sigma-Aldrich, cat\# M5187, RRID:AB_260563), and chicken polyclonal anti-neurofilament (1:1000, Millipore, cat\# AB5539, RRID:AB_11212161) in half concentration blocking buffer. The next day, cochlear pieces were rinsed, incubated in secondary antibodies in half concentration blocking buffer for 2 hours at room temperature, rinsed again, mounted in Fluoromount-G (Southern Biotech) on subbed slides, and coverslipped. Secondary antibodies were goat anti-mouse AF488 (1:1000, Thermo Fisher Scientific cat\# A-10667, RRID:AB_2534057), goat anti-rabbit AF568 (1:1000, Thermo Fisher Scientific, cat\# A-11036, RRID:AB_10563566), and goat anti-chicken AF647 (1:1000, Invitrogen, cat\# A21449, RRID:AB 1500594).

We quantified synaptic ribbons and hair cells at 9 frequency locations along the cochlea, falling at half-octave intervals between 4 and $64 \mathrm{kHz}$. Locations were identified using low-magnification $\sim 5 \times$ photographs and the ImageJ plugin Measure_line, also developed by the Eaton Peabody Laboratories. At each frequency location, we used a confocal microscope (LSM 700 Axio Imager 2; Carl Zeiss) to collect $z$-stacks at $63 \times$ magnification with a z-step size of $0.25 \mu \mathrm{m}$. Care was taken to ensure the z-dimension included all synaptic ribbons. Cochlear image processing was done in ImageJ. Synaptic ribbons were calculated as the total number of CTBP2-labeled puncta throughout the image stack divided by the number of inner hair cells in the image. Cells and their ribbons were included only if the entire cell was visible in the image frame. We also counted the total number of inner and outer hair cells that fit within a 100- $\mu \mathrm{m}$-long window. The number of hair cells in each noise-exposed cochlea was compared to the average number of cells in shamexposed cochleae to calculate cell survival.

\section{Ventral cochlear nucleus immunohistochemistry}

We evaluated labeling of vesicular glutamate transporter 1 (VGLUT1) and glutamic acid decarboxylase 65 (GAD65) in the VCN to identify effects of noise exposure on excitatory and inhibitory synapses, respectively. VGLUT1 is present in auditory nerve terminals in the cochlear nucleus (CN; Gómez-Nieto and Rubio, 2009; Zeng et al., 2009; Lauer et al., 2013). GAD65 is primarily localized to presynaptic GABAergic terminals (Feldblum et al., 1993; Soghomonian and Martin, 1998); most terminals in the VCN that release GABA also release glycine (Juiz et al., 1996).

Procedures were similar to those described by Lauer et al. (2013) and McGuire et al. (2015). Mice were deeply anesthetized, transcardially perfused, and decapitated, as described above. The skull bone was partially removed, and the brain was postfixed overnight. The following day, the brain was dissected from the skull, trimmed, and embedded in gel albumin. Serial sections were cut at 50 $\mu \mathrm{m}$ in the coronal plane and collected in $0.12 \mathrm{M}$ Trisbuffered saline (TBS).

We incubated sections in $0.5 \%$ Triton X-100 (Electron Microscopy Services) for $10 \mathrm{~min}$ at room temperature on a shaker. Sections were then blocked in $1 \%$ normal goat serum for $1 \mathrm{~h}$ at room temperature, rinsed, and incubated overnight in mouse monoclonal anti-GAD65 (1:1000; Ab- cam, cat\# ab26113, RRID:AB_448989) or rabbit polyclonal anti-VGLUT1 (1:1000; Thermo Fisher Scientific, cat\# 48-2400, RRID:AB_2533843) at $4^{\circ} \mathrm{C}$. The following day, we rinsed the sections, incubated in biotinylated goat anti-mouse (1:200; Vector Laboratories, cat\# BA-9200, RRID:AB_2336171) or goat anti-rabbit (1:200; Vector Laboratories, cat\# BA-1000, RRID:AB_2313606) for $1 \mathrm{~h}$, rinsed, and then incubated in avidin-biotin complex (ABC Elite, Vector Labs) for $1 \mathrm{~h}$. We finally stained the sections with a solution of nickel ammonium sulfate and 3-3'diaminobenzidine (Sigma Chemical). For each brain, we omitted the primary antibody for one section and the secondary antibody in an additional section to serve as negative controls. As a positive control, we noted staining of terminals in the cerebellum as has been previously described (Rico et al., 2002; Obata et al., 2008).

\section{Ventral cochlear nucleus immunohistochemical analysis}

Sections that included VCN were photographed in grayscale at $20 \times$ on a microscope (Labophot; Nikon) with mounted CCD camera (Progres; Jenoptik). For sections in which VCN did not fit entirely into the imaging area, we took two or three overlapping photographs and merged them in Photoshop (Adobe Systems) or Fiji (Schindelin et al., 2012) before analysis. All photographs of VCN from both hemispheres of a given mouse were then collected as a single image-stack in FIJI. Using a graphics tablet and stylus (Cintiq 22HD; Wacom), we manually traced a region of interest $(\mathrm{ROI})$ around the $\mathrm{VCN}$ in each image following standard criteria (Willard and Ryugo, 1983). Each case exhibited minor variations in overall illumination and/or staining intensity across its set of sections. To correct for this irregularity, a leveling adjustment was applied to each section such that the mean pixel intensity within each VCN ROI was equivalent across all sections from the mouse without causing over- or undersaturation. Only global (section-wide) adjustments of pixel values were permitted; local manipulations were never made.

To identify positive immunolabeling, a histogram of pixel intensity was constructed based on all pixels within the VCN ROls across all slices. This histogram served as the input for automatic image thresholding. We evaluated the output of all available autothreshold algorithms in Fiji against the results of manual thresholding by a blinded observer on a limited dataset. We determined that of the various available algorithms, triangle and RenyiEntropy most successfully identified stained particles for VGLUT1 and GAD65 labeling, respectively. Furthermore, the algorithms ignored diffuse background labeling such as that noted in negative control sections. Accordingly, these algorithms were applied to our entire dataset. Label/optical density was quantified as the total number of thresholded pixels in a given case divided by the total number of pixels within the entire VCN ROI. With the exception of manual segmentation of VCN borders, all steps were fully automated, thus minimizing the possibility of experimenter bias. 


\section{Cochlear nucleus reconstruction}

Each $\mathrm{CN}$ was reconstructed and manipulated in 3D following previously described methods (Muniak et al., 2013b; Connelly et al., 2017). Briefly, serial-section brightfield photomicrographs through the entire $\mathrm{CN}$ were collected with a $2 \times$ objective and semi-automatically montaged and aligned in TrakEM2 software (Cardona et al., 2012) with the assistance of custom Python scripts. Within TrakEM2, the boundary of the CN was segmented using a graphics tablet (Cintiq 22HD; Wacom) following standard criteria (Willard and Ryugo, 1983). We then exported these outlines to Amira software (Thermo Fisher) and used them to construct 3D surfaces of each CN. In instances where the entirety of the $\mathrm{CN}$ was not included (e.g., exclusion of posterior-most sections of the DCN), the 3D surface reconstruction was left unbounded (i.e., not "closed") at the anterior and/or posterior end; doing so ensured that subsequent alignments in Amira were not influenced by artificial boundaries. Each experimental 3D $\mathrm{CN}$ surface was iteratively aligned, using affine transformations in Amira, to a published 3D template of the mouse CN (Muniak et al., 2013b) until no further improvements to the quality of the fit could be achieved. We quantified the quality of each fit using the root mean square (RMS) distance of vertices of the experimental surface to the template surface. A 3D transformation matrix was subsequently obtained that provides a linear mapping between an individually reconstructed $\mathrm{CN}$ (within the coordinate-frame of TrakEM2) and the CN template. Each hemisphere of a mouse was reconstructed individually, and transformations of the left hemisphere included a reflection over the midline to match the orientation of the $\mathrm{CN}$ model.

\section{Frequency mapping of immunolabeling}

Each image section from the $20 \times$ image-stack used for immunolabeling analysis was imported into TrakEM2 and aligned to its corresponding $2 \times$ counterpart using scaleinvariant feature transforms (Saalfeld et al., 2010). The frequency model of the mouse CN (Muniak et al., 2013b) uses the same virtual coordinate system as the aforementioned 3D CN template. Thus, by concatenating the resulting transform of each high-magnification image with the previously computed $3 \mathrm{D}$ affine transformation, we were able to map every pixel of the image-stack to the $\mathrm{CN}$ frequency model. Accordingly, we could assign frequency values to all pixels within each VCN ROI of a given subject and analyze the results in Matlab. We examined frequency-specific labeling in 1/4-octave bins spanning the frequency range used for audiometric testing $(6-32 \mathrm{kHz})$, with bin-centers of $5.8,6.9,8.2,9.8,11.7,13.9,16.5,19.6$, 23.3, 27.7, and $33.0 \mathrm{kHz}$. Label density within each bin was evaluated independently: we calculated the total number of immunopositive (i.e., thresholded) pixelsderived from the prior auto-thresholding analysis-within a particular $1 / 4$-octave range and divided this by the total number of VCN pixels allocated to the same frequency interval.

\section{Experimental design and statistical analyses}

We exposed 6-week-old CBA/CaJ mice to broadband noise or a sham exposure. After noise or sham-exposure, mice were used in a variety of procedures; the numbers of mice and their sex and age at the time of procedure are listed in Table 1. We trained some mice in CLS procedures. We do not include ABR data or histology from these animals, because, due to the extensive time spent training and testing them, these other procedures are performed at much later time points. In the rest of the animals, we recorded ABRs 1 month post-exposure. Some of these animals were later tested in ASR, while we collected and processed brains and/or cochleae from others. We did not harvest any tissue from mice tested in ASR due to concern that additional exposure to loud sounds during the ASR testing might have uncontrolled effects on anatomy. Half of the brains collected were labeled for VGLUT1 and half for GAD65; both hemispheres were analyzed in all animals. For most animals, we counted SGNs in both cochleae; however, we did not analyze any cochleae that were damaged during dissection or processing. When two cochleae were available for a given subject, the counts for the two cochleae were averaged to obtain a single count per subject. We dissected one cochlea each from an additional subset of animals and counted ribbon synapses and hair cells.

We fitted linear mixed models (LMM) to all ABR data, as well as ASR data, CLS data, and frequency-specific immunohistochemistry data using the nlme package in $\mathrm{R}(\mathrm{R}$ Development Core Team, 2017). Mixed models were used because they can account for repeated measures as well as missing data points. Exposure condition and subject sex were included in all models. Additional variables typically included were frequency and stimulus level, but these variables were excluded when not applicable. In general, model fits were quite good, with an average Nagelkerke pseudo- $R^{2}$ of 0.75 (Lefcheck, 2016; Nakagawa et al., 2017). Pseudo- $R^{2}$ values for the models of ABR thresholds, amplitudes, and latencies were all at least 0.72 , except $\mathrm{p} 2$ amplitudes in response to tones, which had a value of 0.43 . ABR peak ratios of p2:p1 and p4:p1 had models with pseudo- $R^{2}$ s of 0.50 , while that of peak ratio p3:p1 was 0.38 . The models for ASR and CLS had pseudo- $R^{2}$ s of 0.98 and 0.75 , respectively, and those for VCN and inner ear immunohistochemistry were $>0.82$.

We fitted separate models for the ABR thresholds and CLS thresholds, as well as the amplitudes, latencies, and amplitude ratios of each ABR peak. Each model included a weighting term to correct the heteroskedasticity that resulted from differences in variability between the noiseexposed and sham-exposed animals. Amplitude and frequency variables were log-transformed before inclusion in the models to achieve normality, and we also used the poly function to include an orthogonal second-order polynomial frequency term to reflect the shape of the audiogram. In the model for ASR, we corrected heteroskedasticity with a weighting term based on stimulus level.

To assess the effect of noise exposure on CLS detection thresholds relative to $A B R$ thresholds, we fit a linear 


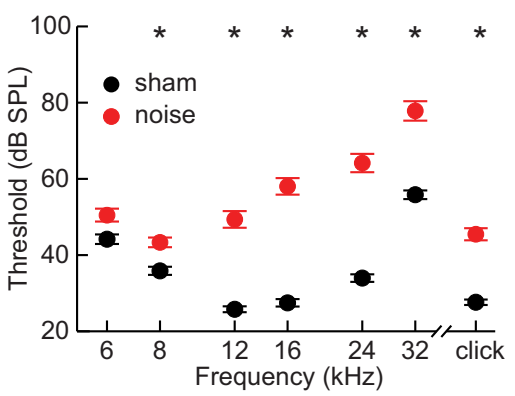

Figure 1. ABR thresholds. Average thresholds for responses to clicks and tones of frequencies ranging from 6 to $32 \mathrm{kHz}$. Threshold was met when the peak-to-peak amplitude of the response was equal to two standards deviations above the average baseline noise amplitude. Error bars represent SEM. Asterisks indicate significant differences between noiseexposed and sham-exposed subjects.

mixed-effects model that included both $A B R$ and CLS thresholds, but also included a "procedure" factor indicating whether a threshold was determined through CLS or ABR. For this analysis, we ignored subject sex due to the smaller number of trained subjects and restricted the data to measurements at frequencies tested in both procedures (i.e., 8, 12, and $16 \mathrm{kHz}$ ).

For all mixed-model analyses, the model included all main effects and all possible interaction terms, excluding the highest-order interaction. Statistics reported reflect an ANOVA based on the fixed effects in the model, and we report partial eta squared as an effect size (Cohen, 1973; Richardson, 2011). We performed post hoc analyses on the models for thresholds, amplitude ratios, ASR data, and frequency-specific immunohistochemistry data with the package Ismeans, using the mvt correction (based on a multivariate $t$ distribution) for multiple comparisons. We used the Istrends post hoc function in the Ismeans package to compare the slopes of the level functions for amplitudes and latencies between the noise-exposed and sham-exposed groups, also using the mvt correction. For post hoc tests, we report Cohen's $d$ as a measure of effect size.

We used two-way ANOVAs to test the effects of noise exposure on spiral ganglion counts and global VCN antibody labeling. ANOVAs were performed using the ANOVAN function in Matlab and in all cases included exposure condition and subject sex as factors. We report partial eta squared effect sizes. An alpha level of 0.05 was used for all statistical tests, and residuals from each test followed a normal distribution.

\section{Results}

\section{Auditory brainstem response}

$A B R$ thresholds were generally higher in noise-exposed mice than in sham-exposed mice (Fig. 1). Thresholds to clicks were significantly higher in noise-exposed animals compared to sham-exposed animals (LMM: $F_{(1,78)}=48.8$, $p<0.001, \eta_{p}^{2}=0.39$ ), and there was no effect of subject sex. There was a significant effect of the interaction of frequency and exposure condition (LMM: $F_{(2365)}=74.0$, $p<0.001, \eta_{\mathrm{p}}^{2}=0.29$ ) on thresholds in response to tones.
Noise-exposed subjects had significantly higher thresholds than sham-exposed subjects in response to all frequencies higher than $6 \mathrm{kHz}$ (all post hoc: $t(78) \geq 7.2, p<$ $0.001, d \geq 0.80$ ), but the magnitude of the effect was greatest at 16 and $24 \mathrm{kHz}$. There was also a significant effect of the frequency $\times$ sex interaction $\left(\operatorname{LMM}: F_{(2,365)}=\right.$ $\left.5.1, p=0.006, \eta_{p}^{2}=0.03\right)$. There was no difference in thresholds between the sexes at $12 \mathrm{kHz}$ and below, but females tended to have lower thresholds at frequencies above $12 \mathrm{kHz}$.

The peak-to-trough amplitudes of ABR wave 1 (referred to hereafter as $\mathrm{p} 1$ ) in response to clicks and tones of 8,16 , and $32 \mathrm{kHz}$ are plotted in Fig. $2 A$ (top). Trends for 6,12 , and $24 \mathrm{kHz}$ were similar to those evident in the responses to 8,16 , and $32 \mathrm{kHz}$, respectively. Amplitudes of $\mathrm{p} 1$ in response to clicks and tones of all frequencies increased as a function of intensity (Fig. 2A) for both noise-exposed and sham-exposed mice. However, in response to clicks and tones with frequencies above $8 \mathrm{kHz}$, the amplitudes of $\mathrm{p} 1$ were considerably smaller in noise-exposed mice compared to sham-exposed mice (Fig. 2A). This point is illustrated by comparing the grand average ABR traces in Fig. $2 C$. The slopes of the level functions were also different. That is, the difference in amplitude between noiseexposed and sham-exposed animals increased as a function of level. This is reflected for the responses to clicks in a significant exposure $\times$ level interaction (LLM: $F_{(1390)}=6.9, p=0.009, \eta_{p}^{2}=0.02$ ). For responses to tones, the difference in slopes varied across frequency, as indicated by a significant exposure $\times$ frequency $\times$ level interaction (LLM: $\left.F_{(2,2368)}=44.8, p<0.001, \eta_{p}^{2}=0.04\right)$. The slopes were significantly different between noiseexposed and sham-exposed animals for tones of all frequencies (all post hoc: $t(2368) \geq 11.8, p<0.001, d \geq 1.3$ ) and clicks (post hoc: $t(390)=16.0, p<0.001, d=1.77$ ). However, while the slopes were steeper for shamexposed animals in response to clicks and frequencies from 12 to $32 \mathrm{kHz}$, they were steeper for noise-exposed animals at 6 and $8 \mathrm{kHz}$. There was also an effect of sex for some of the level functions for responses to tones, as reflected in a significant sex $\times$ frequency $\times$ level interaction (LLM: $\left.F_{(2,2368)}=6.7, p=0.001, \eta_{\mathrm{p}}^{2}=0.01\right)$ and a significant sex $\times$ exposure $\times$ level interaction (LLM: $\left.F_{(2,2368)}=4.6, p=0.033, \eta_{p}^{2}=0.01\right)$. Males had faster slopes than females at 6 and $8 \mathrm{kHz}$, but females had faster slopes at 12 and $16 \mathrm{kHz}$; this effect was larger in control mice than exposed mice.

$A B R$ latencies of $p 1$ typically decreased as a function of intensity (Fig. 2B), consistent with previous studies in a variety of species (Overbeck and Church, 1992; Zhou et al., 2006; Dehmel et al., 2012a). There was some variation in the slopes of the level functions between noiseexposed and sham-exposed mice and across frequency, reflected in a significant exposure $\times$ level interaction for responses to clicks (LMM: $F_{(1390)}=38.6, p<0.001, \eta_{\mathrm{p}}^{2}=$ 0.09 ) and a significant exposure $\times$ frequency $\times$ level interaction for responses to tones (LMM: $F_{(2,2368)}=36.1$, $\left.p<0.001, \eta_{p}^{2}=0.03\right)$. A post hoc test on the slopes indicated differences in noise-exposed and shamexposed animals for tones at $6,12,16$, and $32 \mathrm{kHz}$ (all 
A
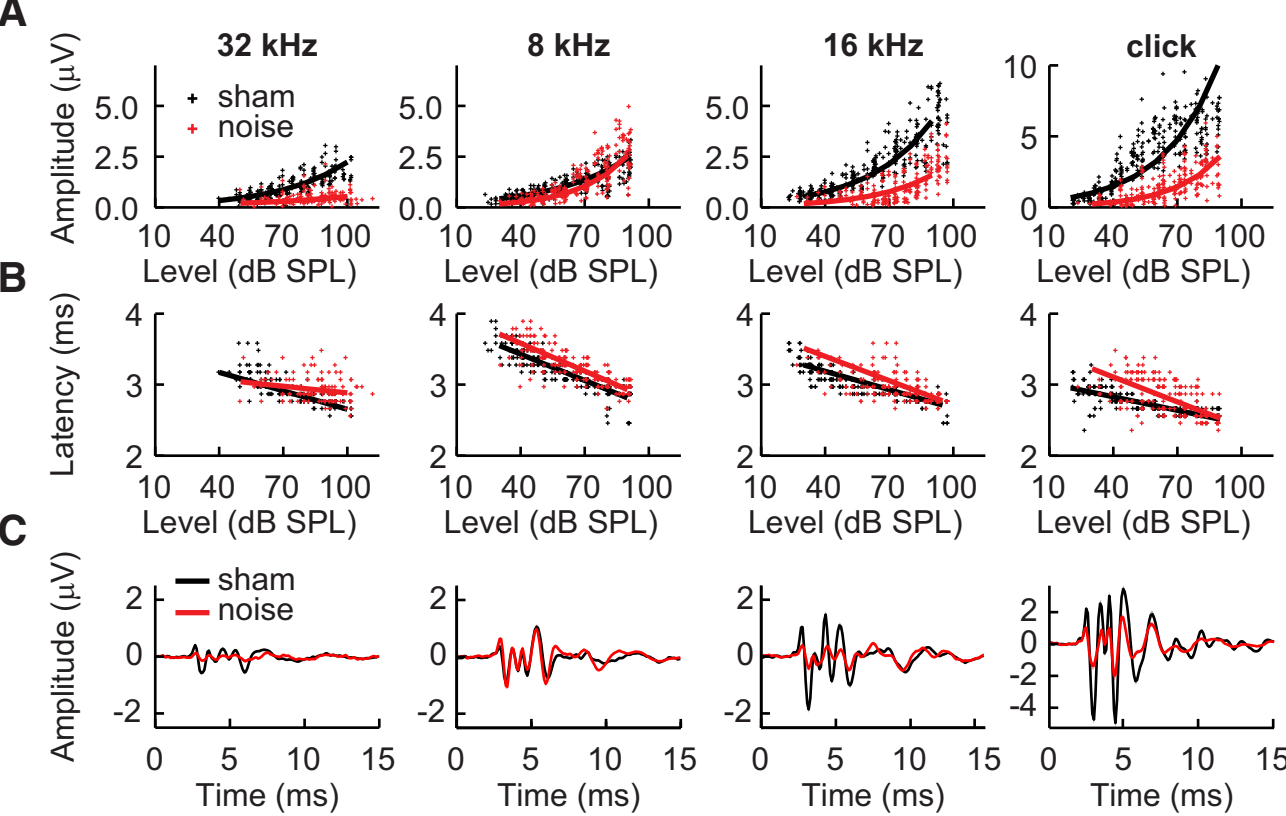

Figure 2. Measurements of ABR peak 1. A, Amplitudes. $\boldsymbol{B}$, Latencies of peak 1 in response to clicks and tones of 8 , 16 , and $32 \mathrm{kHz}$. Legend in $\boldsymbol{A}$ also applies to $\boldsymbol{B}$. Axis in $\boldsymbol{B}$ also applies to $\boldsymbol{A}$. Solid lines indicate predictions of means made by linear mixed models fit to the data. $\boldsymbol{C}$, Waveforms averaged across all subjects for each exposure condition. Solid lines represent means, and lighter shading indicates the SEM.

post hoc: $4.0 \leq t(2368) \leq 6.6, p<0.001,0.44 \leq d \leq 0.73)$; however, the direction of the differences varied across frequency, and the sizes of the effects were much smaller compared to the effects on amplitudes (compare max latency $d=0.73$ to min amplitude $d=1.30$ ), suggesting that this interaction may not be functionally important. There was also a significant effect of the sex $x$ frequency $\times$ level interaction on latencies of responses to tones (LMM: $\left.F_{(2,2368)}=10.7, p<0.001, \eta_{p}^{2}=0.01\right)$, but no effects of sex on responses to clicks. The slopes of the level functions were steeper for females than males at 6 and $8 \mathrm{kHz}$, but did not differ at higher frequencies.

Amplitudes of the later ABR peaks (peaks 2-4) increased as a function of increasing level and were generally reduced in noise-exposed animals compared to sham-exposed animals (Fig. $3 A$ ). There was a significant effect of the exposure $\times$ level interaction on amplitudes of responses to clicks for p2 (LMM: $F_{(1390)}=3.9, p=0.050$, $\left.\eta_{\mathrm{p}}^{2}=0.01\right)$ and p3 (LMM: $F_{(1390)}=6.9, p=0.009, \eta_{p}^{2}=$ $0.02)$, but not $\mathrm{p} 4$. However, the main effects of exposure $\left(\right.$ LMM: $\left.F_{(1,78)}=29.4, p<0.001, \eta_{\mathrm{p}}^{2}=0.27\right)$ and level $\left(\right.$ LMM: $\left.F_{(1390)}=430.0, p<0.001, \eta_{\mathrm{p}}^{2}=0.52\right)$ on $\mathrm{p} 4$ were both significant. For responses to tones, there were significant effects of the exposure $\times$ frequency $\times$ level interactions on the amplitudes of $\mathrm{p} 2\left(\mathrm{LMM}: F_{(2,2368)}=7.4\right.$, $\left.p=0.001, \eta_{\mathrm{p}}^{2}=0.01\right)$ and $\mathrm{p} 4\left(\mathrm{LMM}: F_{(2,2309)}=19.7, p<\right.$ $\left.0.001, \eta_{\mathrm{p}}^{2}=0.02\right)$. None of the three-way interactions had significant effects on p3. However, there were significant effects of the exposure $\times$ level $\left(\mathrm{LMM}: F_{(2,2368)}=4.7, p=\right.$ $\left.0.031, \eta_{\mathrm{p}}^{2}=0.01\right)$, exposure $\times$ frequency $\left(\mathrm{LMM}: F_{(2,2368)}=\right.$ $\left.5.7, p=0.003, \eta_{\mathrm{p}}^{2}=0.01\right)$, and level $\times$ frequency (LMM: $\left.F_{(2,2368)}=28.711, p<0.001, \eta_{p}^{2}=0.02\right)$ interactions. The slopes of the level functions for p2, p3, and p4 were significantly steeper in sham-exposed animals for clicks and frequencies above $8 \mathrm{kHz}$ (all post hoc: $t(2368) \geq 4.8$, $p<0.001, d \geq 0.53$ ) except for $\mathrm{p} 2$ at $32 \mathrm{kHz}$. Slopes for level functions were significantly steeper in noiseexposed animals at $6 \mathrm{kHz}$ for $\mathrm{p} 2$ (post hoc: $t(2368)=-5.7$, $p<0.001, d=-0.63$ ) and at 6 and $8 \mathrm{kHz}$ for $\mathrm{p} 4$ (post hoc: $6 \mathrm{kHz}: t(2368)=-8.9, p<0.001, d=-0.99 ; 8 \mathrm{kHz}:$ $t(2368)=-3.5, p=0.002, d=-0.39$ ).

Both p2 and p4 of tones were also influenced by a significant effect of the sex $\times$ frequency $\times$ level interaction (LMM: p2: $F_{(2,2368)}=6.1, p=0.002, \eta_{\mathrm{p}}^{2}=0.01 ; \mathrm{p} 4$ : $\left.F_{(2,2368)}=3.1, p=0.047, \eta_{p}^{2}=0.01\right)$. There were also significant effects of the sex $\times$ frequency $\times$ exposure interaction (LMM: $\left.F_{(2,2368)}=4.0, p=0.019, \eta_{p}^{2}=0.01\right)$ and the sex $\times$ level $\times$ exposure interaction $\left(\mathrm{LMM}: F_{(2,2368)}=4.2\right.$, $p=0.042, \eta_{\mathrm{p}}^{2}=0.01$ ) on amplitudes of $\mathrm{p} 2$ for responses to tones and of the sex $\times$ level interaction $\left(F_{(1390)}=6.1\right.$, $p=0.014, \eta_{p}^{2}=0.02$ ) on $p 4$ of responses to clicks. For $\mathrm{p} 2$, the slopes for males were not dependent on frequency, but slopes for females decreased as a function of frequency, such that females had steeper slopes than males at low frequencies but shallower slopes at higher frequencies. Slopes for $\mathrm{p} 4$ generally decreased in both sexes as a function of frequency, but females had consistently steeper slopes than males across frequency.

Similar trends in latency were observed for the latencies of late peaks as for $\mathrm{p} 1$ (c.f. Figs. $2 B$ and $3 B$ ). For all three later peaks of responses to clicks, the interaction between exposure and level was significant (LMM: p2: $F_{(1390)}=$ 28.0, $p<0.001, \eta_{\mathrm{p}}^{2}=0.07$; p3: $F_{(1390)}=34.7, p<0.001$, $\left.\eta_{\mathrm{p}}^{2}=0.08 ; \mathrm{p} 4: F_{(1390)}=61.2, p<0.001, \eta_{\mathrm{p}}^{2}=0.14\right)$. The interactions between exposure condition, frequency, and level had significant effects on all three of the later peaks 
A
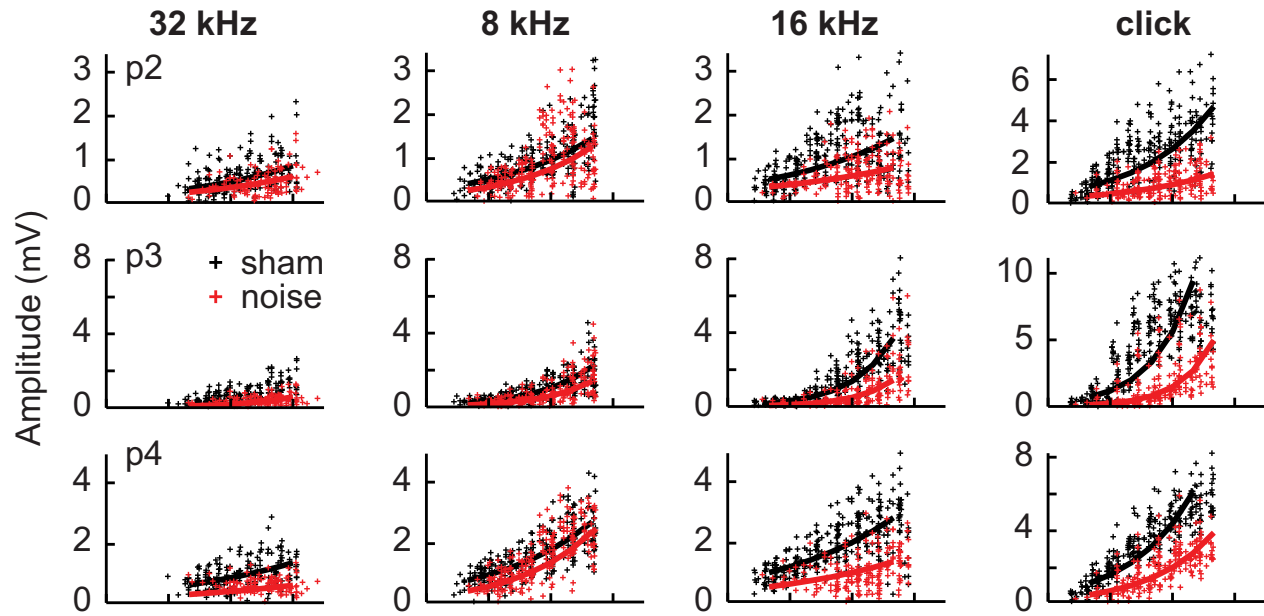

B
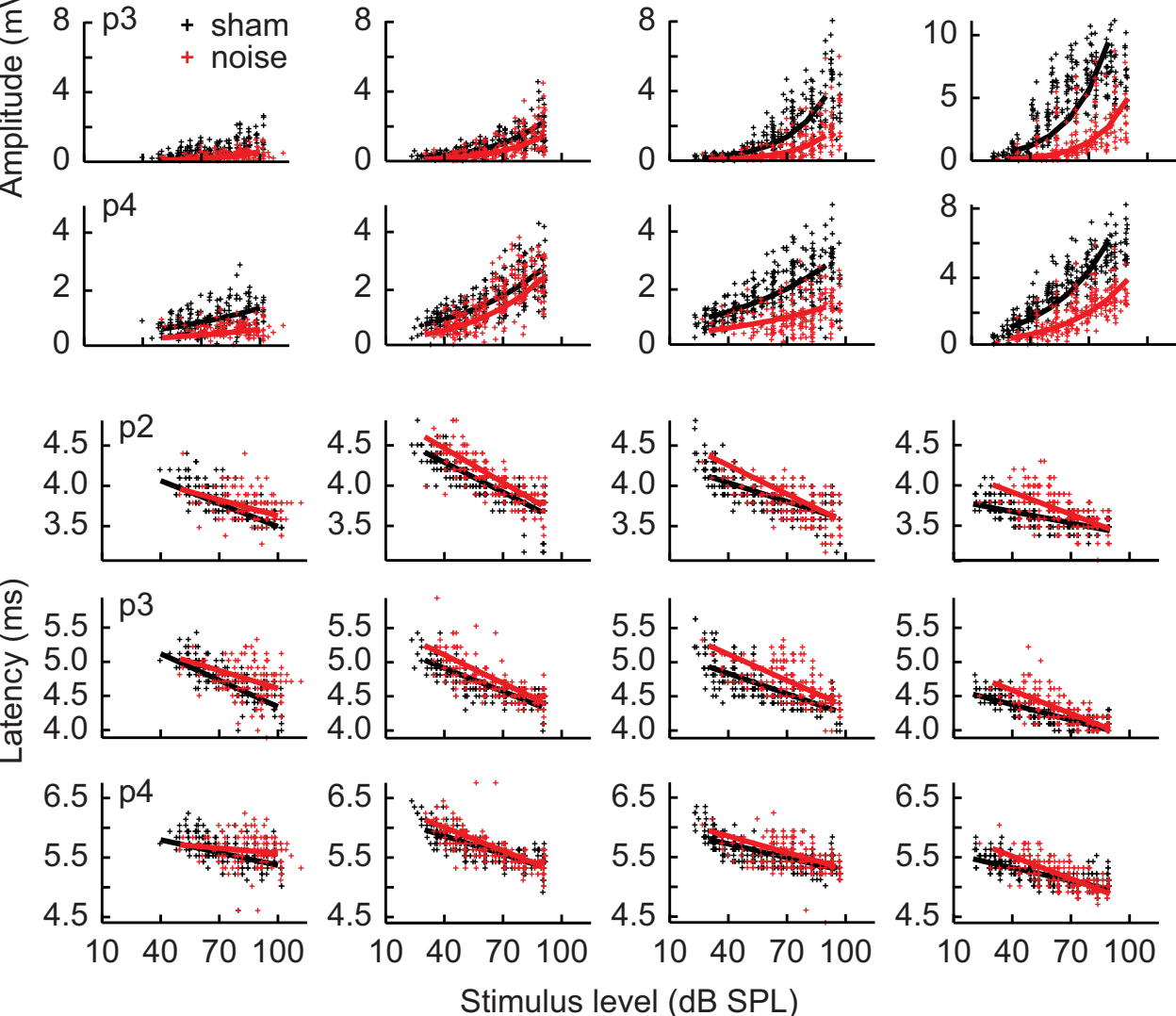

Stimulus level (dB SPL)

Figure 3. Amplitudes and latencies of ABR peaks 2-4. A, Amplitudes of p2 (top), p3 (middle), and p4 (bottom) in response to clicks and tones of 8,16 , and $32 \mathrm{kHz}$. $\boldsymbol{B}$, Latencies for the same corresponding peaks in $\boldsymbol{A}$. Legend in $\boldsymbol{A}$ corresponds to all panels. Axis in $\boldsymbol{B}$ (bottom) corresponds to all panels. Solid lines indicate predictions made by linear mixed models.

of responses to tones (LMM: p2: $F_{(2,2368)}=16.8, p<$ $0.001, \eta_{\mathrm{p}}^{2}=0.01 ; \mathrm{p} 3: F_{(2,2368)}=13.0, p<0.001, \eta_{\mathrm{p}}^{2}=$ $\left.0.01 ; \mathrm{p} 4: F_{(2,2368)}=13.1, p<0.001, \eta_{\mathrm{p}}^{2}=0.01\right)$. However, again post hoc tests revealed the effects of the exposure $\times$ level interactions to be quite small and variable across frequency (all post hoc: $2.9 \leq t(2368) \leq 7.6, p \leq 0.017$, $0.44 \leq d \leq 0.73$ ). The sex $\times$ level $\times$ frequency interaction was also significant for $\mathrm{p} 3$ of responses to tones (LMM: $\left.F_{(2,2368)}=5.6, p=0.004, \eta_{\mathrm{p}}^{2}=0.01\right)$, reflecting a similar trend as that observed for $\mathrm{p} 1$ wherein females had steeper slopes than males only at 6 and $8 \mathrm{kHz}$.

\section{Hyperactivity assessed via ABR}

To evaluate whether the central auditory system exhibited hyperactivity relative to peripheral activity in noiseexposed mice, we calculated the ratio of the amplitudes of peaks 2-4 relative to peak 1 for all responses. The results for stimuli at 60,70 , and $80 \mathrm{~dB}$ SPL are plotted in Fig. 4. For responses to clicks, there were significant effects of the exposure $\times$ level interaction on p2:p1 (Fig
4A; LMM: $\left.F_{(1268)}=24.9, p<0.001, \eta_{\mathrm{p}}^{2}=0.09\right)$, p3:p1 (Fig 4B; LMM: $\left.F_{(1268)}=11.4, p=0.001, \eta_{p}^{2}=0.04\right)$, and p4:p1 (Fig 4C; LMM: $\left.F_{(1268)}=19.5, p<0.001, \eta_{\mathrm{p}}^{2}=0.07\right)$ amplitude ratios. No effects that included sex as a variable were significant. We performed post hoc contrasts at the stimulus levels 60,70 , and $80 \mathrm{~dB}$ SPL. These tests revealed that noise-exposed animals had significantly larger p2:p1 and p4:p1 amplitude ratios than shamexposed animals, and that the size of the effect was inversely correlated with stimulus level (Table 2).

In responses to tones, there was a general trend for ratios of $\mathrm{p} 2: \mathrm{p} 1$ and $\mathrm{p} 4: \mathrm{p} 1$ to be larger in noise-exposed animals at frequencies of $\sim 12 \mathrm{kHz}$ and higher, but equal or larger in sham-exposed animals at frequencies below $12 \mathrm{kHz}$, indicating hyperactivity in the bushy cell-driven pathways in the region of hearing loss. Ratios also differed as a function of level, resulting in significant exposure $\times$ frequency $\times$ level interactions for each peak ratio (LMM: p2:p1: $F_{(2,1991)}=8.2, p<0.001, \eta_{\mathrm{p}}^{2}=0.01 ; \mathrm{p} 3: \mathrm{p} 1$ : $F_{(2,1991)}=19.6, p<0.001, \eta_{p}^{2}=0.02 ; \mathrm{p} 4: \mathrm{p} 1: F_{(2,1991)}=$ 

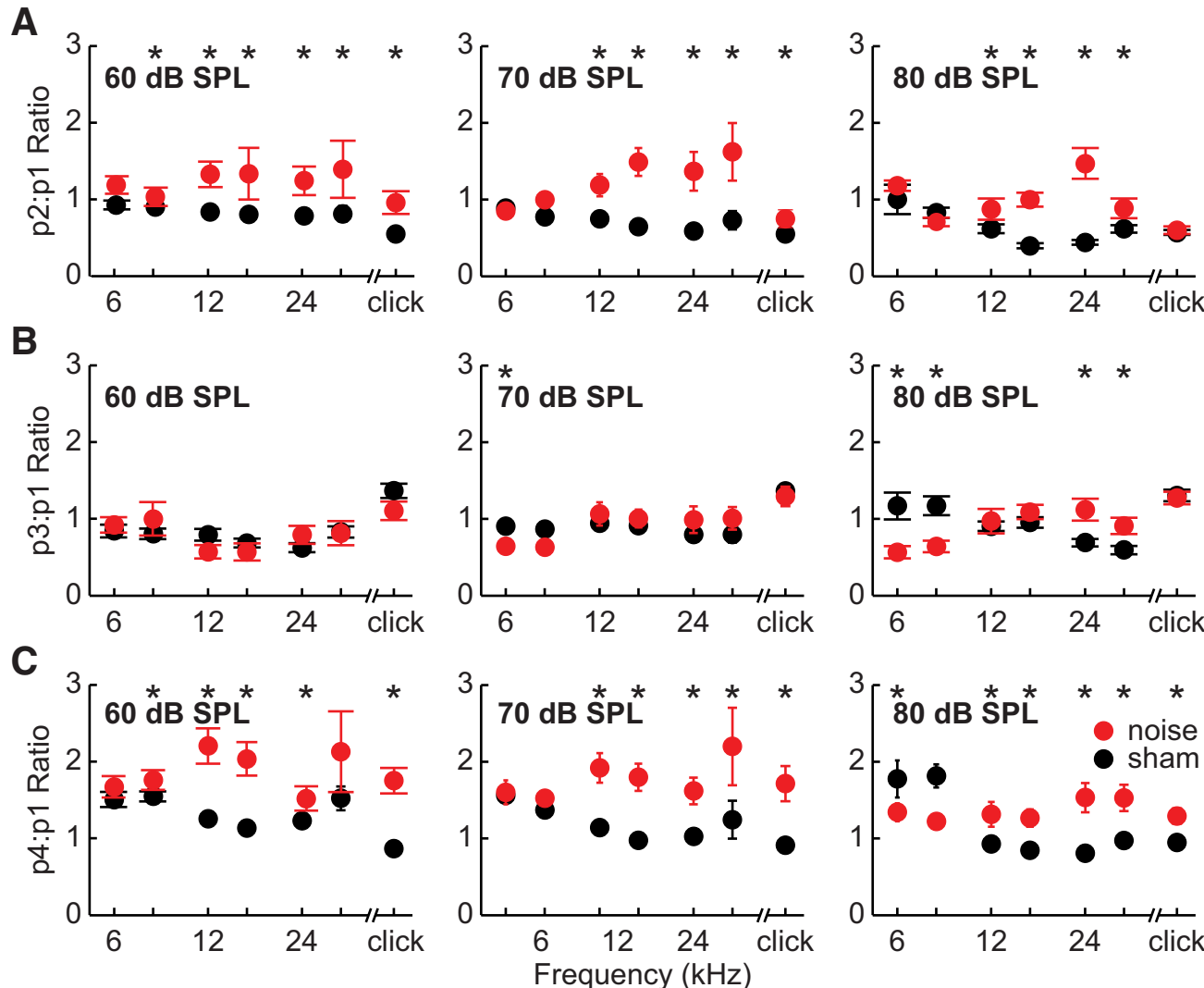

Figure 4. Hyperactivity in bushy cell-driven pathways. Plotted are average ratios of amplitudes of ABR peak 2 relative to peak 1 (A), peak 3 relative to peak $1(\boldsymbol{B})$, and peak 4 relative to peak $1(\boldsymbol{C})$. Ratios are plotted for responses to clicks and tones of frequencies from 6 to $32 \mathrm{kHz}$ at stimulus levels of $60 \mathrm{~dB}$ SPL (left), $70 \mathrm{~dB}$ SPL (middle), and $80 \mathrm{~dB}$ SPL (right). Error bars represent SEM. Legend applies to all panels. Asterisks indicate significant differences between noise-exposed and sham-exposed mice. Ratios larger than those of sham-exposed animals indicate hyperactivity, while smaller ratios indicate hypoactivity.

17.4, $\left.p<0.001, \eta_{\mathrm{p}}^{2}=0.01\right)$. Post hoc tests revealed that noise-exposed animals typically had significantly larger p2:p1 ratios at frequencies of $12 \mathrm{kHz}$ and higher (all post hoc: $t(78) \geq 2.8, p \leq 0.050, d \geq 0.31$ ). While effect sizes decreased as a function of stimulus level at 12 and $16 \mathrm{kHz}$ $(d=0.6-0.39$ at $12 \mathrm{kHz}$ and $0.72-0.69$ at $16 \mathrm{kHz}$ ), they increased as a function of level at 24 and $32 \mathrm{kHz}(d=$ $0.60-1.15$ at $24 \mathrm{kHz}$ and $0.31-0.98$ at $32 \mathrm{kHz}$ ). In general, there were no differences between amplitude ratios of noise and sham-exposed mice at 6 or $8 \mathrm{kHz}$, with the exception of $8 \mathrm{kHz}$ at $60 \mathrm{~dB}$ SPL, where noise-exposed mice had larger ratios (post hoc: $t(78)=3.6, p=0.006$, $d=0.39$ ).

Table 2. Post hoc tests comparing click amplitude ratios for noise and sham-exposed mice

\begin{tabular}{llllll}
\hline Ratio & Level & $\mathrm{df}$ & $t$ & $p$ & $d$ \\
p2:p1 & 60 & 178 & -5.7 & $<0.001$ & -0.63 \\
& 70 & 1.78 & -3.1 & 0.006 & -0.34 \\
& 80 & 1.78 & -0.1 & 0.986 & -0.02 \\
p3:p1 & 60 & 1.78 & 2.3 & 0.041 & 0.25 \\
& 70 & 1.78 & 1.3 & 0.269 & 0.15 \\
& 80 & 1.78 & 0.3 & 0.904 & 0.03 \\
p4:p1 & 60 & 1.78 & -9.9 & $<0.001$ & -1.10 \\
& 70 & 1.78 & -7.7 & $<0.001$ & -0.85 \\
& 80 & 1.78 & -3.5 & 0.002 & -0.39
\end{tabular}

Most p3:p1 ratios did not differ significantly between noise- and sham-exposed animals. Exceptions occurred almost exclusively at the highest stimulus level examined, $80 \mathrm{~dB}$ SPL, and showed frequency dependencies similar to those noted earlier. At $80 \mathrm{~dB}$ SPL, noise-exposed mice had larger ratios than sham-exposed mice at $24 \mathrm{kHz}$ (post hoc: $t(78)=3.7, p=0.003, d=0.41$ ) and $32 \mathrm{kHz}$ (post hoc: $t(78)=3.7, p=0.004, d=0.40)$, but smaller ratios at $6 \mathrm{kHz}$ (post hoc: $t(78)=5.3, p<0.001, d=0.58$ ) and 8 $\mathrm{kHz}$ (post hoc: $t(78)=3.9, p=0.002, d=0.44$ ). Noiseexposed mice also had smaller ratios at $6 \mathrm{kHz}$ at $70 \mathrm{~dB}$ (post hoc: $t(78)=3.2, p=0.016, d=0.35$ ).

p4:p1 ratios were larger in noise-exposed animals compared to sham-exposed animals at $12 \mathrm{kHz}$ and higher for all levels examined (all post hoc: $t(78) \geq 3.3, p \leq 0.012, d \geq$ 0.37 ), with the exception of $32 \mathrm{kHz}$ at $60 \mathrm{~dB}$ SPL where there was no significant difference. Ratios of p4:p1 were also significantly larger in noise-exposed mice than shamexposed at $8 \mathrm{kHz}$ at $60 \mathrm{~dB}$ SPL (post hoc: $t(78)=4.5, p<$ $0.001, d=0.50$ ), but smaller at $6 \mathrm{kHz}$ at $80 \mathrm{~dB}$ SPL (post hoc: $t(78)=4.7, p<0.001, d=0.51$ ). Similar to $p 2$ : p1 ratios, effect sizes of $p 4: p 1$ ratios decreased as a function of level at $12 \mathrm{kHz}(d=0.77-0.37)$ and $16 \mathrm{kHz}(d=0.83-0.67)$, but increased as a function of level at $24 \mathrm{kHz}(d=0.58-0.95)$ and $32 \mathrm{kHz}(d=0.21-0.73)$. There were also significant effects of the frequency $\times$ level $\times$ sex interactions on p2:p1 


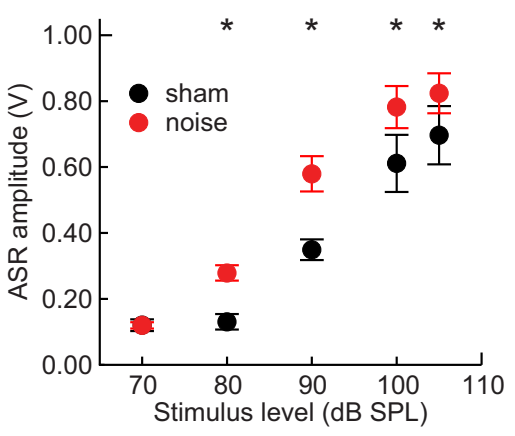

Figure 5. Acoustic startle reflex. Average relative startle responses to broadband noise bursts ranging from 70 to $105 \mathrm{~dB}$ SPL. Error bars represent SEM. Asterisks indicate significant differences between groups.

ratios (LMM: $\left.F_{(2,1991)}=17.1, p<0.001, \eta_{\mathrm{p}}^{2}=0.02\right), \mathrm{p} 3: \mathrm{p} 1$ ratios $\left(\mathrm{LMM}: F_{(2,1991)}=7.2, p=0.001, \eta_{\mathrm{p}}^{2}=0.01\right)$, and $\mathrm{p} 4 \mathrm{p} \mathrm{p} 1$ ratios $\left(\mathrm{LMM}: F_{(2,1991)}=15.0, p<0.001, \eta_{\mathrm{p}}^{2}=0.02\right)$. For most levels and frequencies, females had larger wave ratios than males, but the differences were small and any observed dependence on level was inconsistent across frequency.

\section{Acoustic startle reflex}

In all animals, a growth in mean ASR amplitude was observed with increasing startle stimulus level (Fig. 5). Mean ASR amplitude was greater for the noise-exposed group compared to the sham-exposed group across all but the lowest stimulus level of $70 \mathrm{~dB}$ SPL, which does not typically elicit a startle response. A mixed model revealed a significant effect of the exposure condition $\times$ level interaction $\left(\mathrm{LMM}: F_{(1,81)}=14.0, p<0.001, \eta_{\mathrm{p}}{ }^{2}=\right.$ $0.15)$. Subsequent post hoc tests indicated that the effect of noise exposure was significant at all levels except 70 $\mathrm{dB}$ SPL (all post hoc: $t(18) \geq 3.3, p \leq 0.011, d \geq 0.72$ ). Males had larger ASR amplitudes than females at levels above $70 \mathrm{~dB}$ SPL, but the size of the effect increased as a function of level, as indicated by a significant sex $\times$ level interaction $\left(\mathrm{LMM}: F_{(1,81)}=9.6, p=0.003, \eta_{p}^{2}=0.11\right)$.

\section{Conditioned lick suppression}

We measured behavioral detection thresholds to determine if auditory function was maintained in mice that had been noise-exposed. All animals showed lick suppression rates of at least $80 \%$ above $\sim 70 \mathrm{~dB}$ (Fig. 6 A). All animals also showed linear reaction times as a function of stimulus level, with noise-exposed mice typically having longer reaction times (Fig. 6B). Noise-exposed animals had higher CLS thresholds than sham-exposed mice, ranging from $\sim 4.5 \mathrm{~dB}$ higher at $8 \mathrm{kHz}$ to $\sim 20 \mathrm{~dB}$ higher at $16 \mathrm{kHz}$ (Fig. 6C). There was a significant interaction between frequency and exposure condition (LMM: $F_{(2,32)}=6.6, p=$ $0.004, \eta_{p}^{2}=0.29$ ), with post hoc tests revealing a significant difference between noise-exposed and shamexposed mice only at $16 \mathrm{kHz}$ (post hoc: $t(12)=2.7, p=$ $0.001, d=1.42$ ).
A

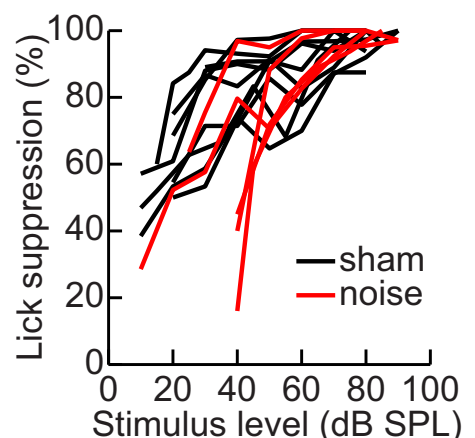

C

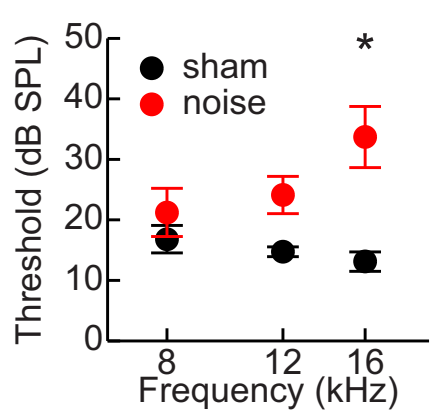

B

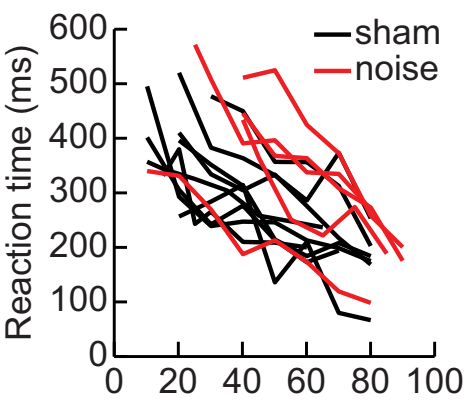

Stimulus level (dB SPL)

D

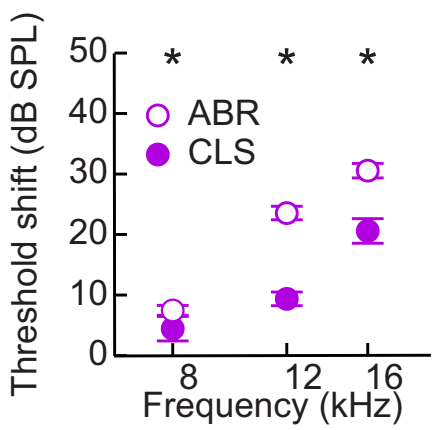

Figure 6. Behavioral detection thresholds. A, Lick suppression rates for noise-exposed and sham-exposed mice for detection of 16 $\mathrm{kHz}$ tone. $\boldsymbol{B}$, Response times for the data in $\boldsymbol{A}$. $\boldsymbol{C}$, CLS thresholds for noise-exposed and sham-exposed mice. Error bars indicate SEM. Asterisks indicate significant differences between groups. $\boldsymbol{D}$, Difference between thresholds of noise-exposed and shamexposed mice as determined from CLS or ABR. Error bars indicate SEM. Asterisks indicate significant differences between the threshold differences for CLS and ABR. 

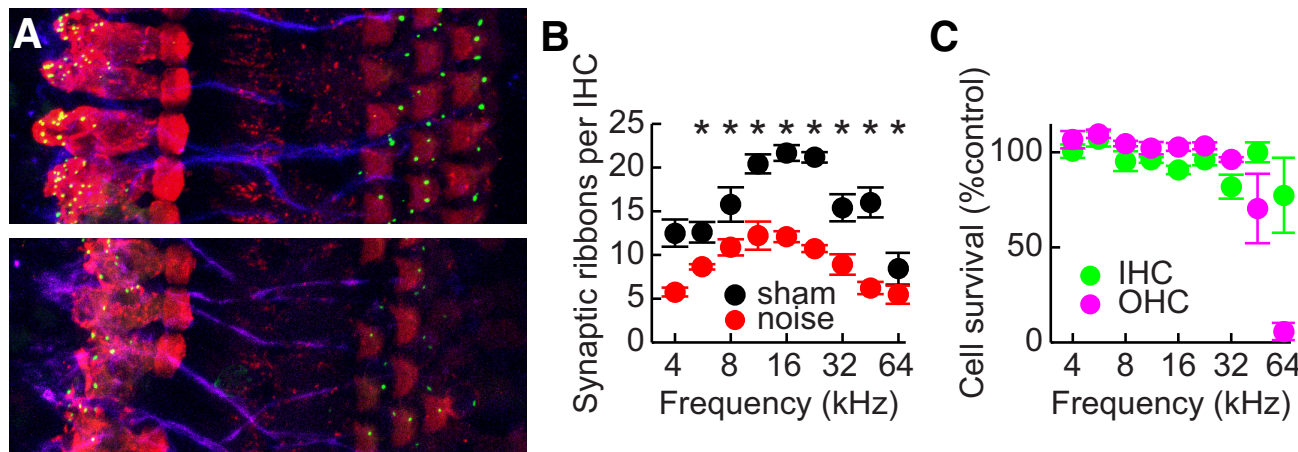

Figure 7. Inner ear immunolabeling. $\boldsymbol{A}$, Example maximum intensity images of cochleae from a sham-exposed (top) and noiseexposed (bottom) mouse at $32 \mathrm{kHz}$. Cochleae were immunolabeled for CTBP2 (green), myosin 6 (red), and neurofilament (blue). Scale bar equals $10 \mu \mathrm{m}$. $\boldsymbol{B}$, Average counts of ribbon synapses per inner hair cell as a function of frequency. Error bars indicate SEM. Asterisks indicate significant differences between groups. $\boldsymbol{C}$, Average percentages of hair cells remaining in noise-exposed cochleae relative to the averages for sham-exposed cochleae. Error bars indicate SEM.

Importantly, the differences in CLS thresholds were much smaller than the differences in ABR thresholds between noise-exposed and sham-exposed animals, which ranged from $\sim 8$ to $\sim 30 \mathrm{~dB}$ (Fig. $6 D$ ). A mixed model that included both $A B R$ and CLS thresholds revealed a significant influence of the exposure $\times$ procedure interaction (LMM: $\left.F_{(1,92)}=8.1, p=0.012, \eta_{\mathrm{p}}{ }^{2}=0.07\right)$, indicating that the effect of noise exposure observed through ABRs was significantly different from the effect observed through CLS. Post hoc tests revealed that this was true across all three frequencies (all post hoc: $t(92) \geq 2.8, p \leq 0.006, d \geq 0.29$ ).

\section{Spiral ganglion neuron counts}

Stereological quantification of spiral ganglion neurons indicated that noise-exposed mice experienced a $\sim 14 \%$ loss of SGNs (mean \pm SD sham $=7311 \pm 595$ cells; noise $=$ $6262 \pm 717$ cells; ANOVA: $F_{(1,15)}=10.6, p=0.005, \eta_{p}^{2}=$ 0.42 ). There was no significant effect of subject sex. Loss of SGNs would result in a decrease in the input to the central auditory system, consistent with the smaller size observed in ABR peak 1 amplitudes of noise-exposed mice.

\section{Inner ear immunohistochemistry}

Example images of cochleae labeled for CTBP2 from sham-exposed and noise-exposed mice are shown in Fig. $7 A$. Noise-exposed mice had about half as many ribbon synapses as sham-exposed mice at frequencies between 11 and $45 \mathrm{kHz}$ (Fig. 7B). In a linear mixed model, the interaction between frequency and exposure condition was significant (LMM: $\left.F_{(2,56)}=3.9, p=0.03, \eta_{\mathrm{p}}{ }^{2}=0.12\right)$. The exposure condition had a significant influence on synapse counts at all frequencies except $4 \mathrm{kHz}$ (all post hoc: $t(6) \geq 3.4, p \leq 0.046, d \geq 1.21$ ). Inner hair cells were well-preserved in noise-exposed mice, with a decrease of $\sim 20 \%$ at 32 and $64 \mathrm{kHz}$. There was a $\sim 30 \%$ loss of outer hair cells in noise-exposed mice at $45 \mathrm{kHz}$, with a drastic loss of $\sim 95 \%$ at $64 \mathrm{kHz}$.

\section{Ventral cochlear nucleus immunohistochemistry \\ Examples of VGLUT1 and GAD65 labeling are shown in Fig. 8. Fig. $9 A, B$ illustrates an example of the results of autothresholding in a section labeled for GAD65. Across}

the entire VCN, there was slightly less VGLUT1 labeling in noise-exposed animals compared to sham-exposed animals (Fig. 8A). However, this effect was not statistically significant. Noise-exposed mice did have significantly less GAD65 labeling than sham-exposed mice (Fig. 8B; ANOVA: $\left.F_{(1,9)}=7.4, p=0.024, \eta_{\mathrm{p}}{ }^{2}=0.45\right)$. Subject sex had no effect on either type of labeling.

\section{Frequency distribution of immunolabeling in VCN}

To determine if the global changes in VGLUT1 and GAD65 labeling were frequency specific, we reconstructed each nucleus in 3D, fitted the reconstructions to a template of the entire CN (Muniak et al., 2013b), and mapped the frequency information from the template to the reconstruction (Fig. $9 C-F$ ). The fit quality of the template alignments was similar to that reported previously for mice of the same strain (mean RMS error \pm SD $38.6 \pm$ $4.8 \mu \mathrm{m}$; Connelly et al., 2017).

The difference between VGLUT1 labeling in noise and sham-exposed mice increased as a function of frequency (Fig. 10A), reflected in a significant interaction between exposure status and frequency (LMM: $F_{(2114)}=28.3, p<$ $0.001, \eta_{\mathrm{p}}^{2}=0.33$ ). Post hoc tests revealed significant differences at two of the highest frequencies examined (post hoc: $23.3 \mathrm{kHz}: t(8)=2.7, p=0.048, d=0.77 ; 27.7$ $\mathrm{kHz}: t(8)=2.7, p=0.046, d=0.78$ ). While not quite reaching significance after correction for multiple comparisons, differences at the two closest frequencies were of a similar magnitude (post hoc: $19.6 \mathrm{kHz}: t(8)=2.5, p=$ $0.058, d=0.73 ; 33 \mathrm{kHz}: t(8)=2.6, p=0.054, d=0.75)$. There was a significant effect of the interaction between sex and frequency (LMM: $F_{(2114)}=10.7, p<0.001, \eta_{p}^{2}=$ 0.16 ), although the size of this effect was about half that of the exposure status $\times$ frequency effect. Females had more labeling at lower frequencies than males, and while labeling decreased in both sexes as a function of frequency, the amount decreased more in females such that they had less labeling than males at the highest frequencies examined. The interaction between exposure status and sex was not significant.

There was no obvious frequency dependence in the differences in GAD65 labeling between noise and sham- 
A

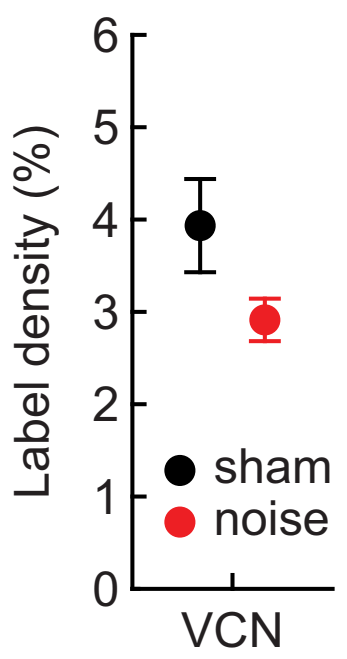

B

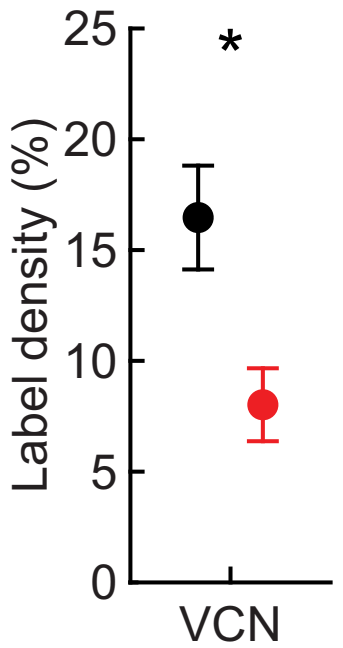

VGLUT1
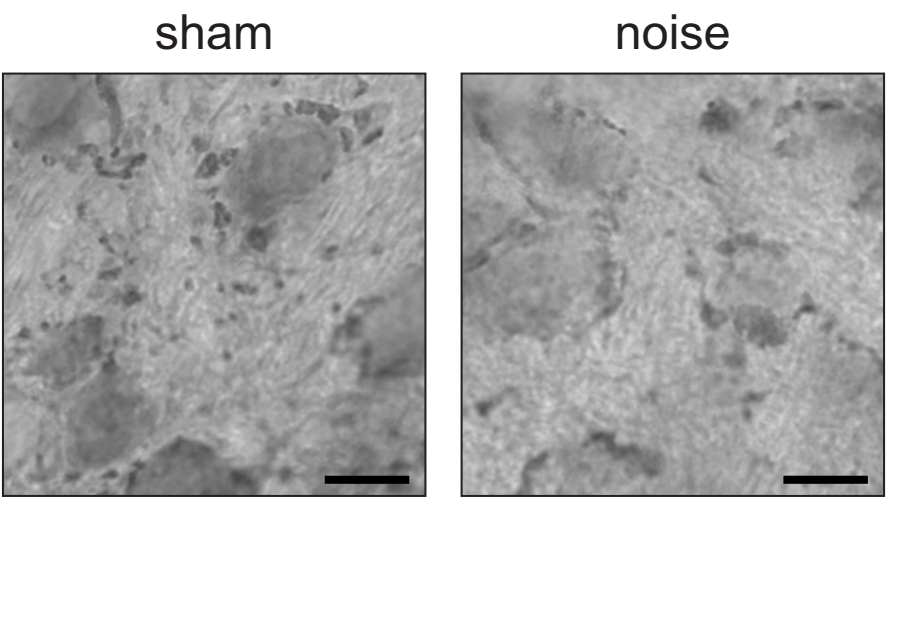

GAD65

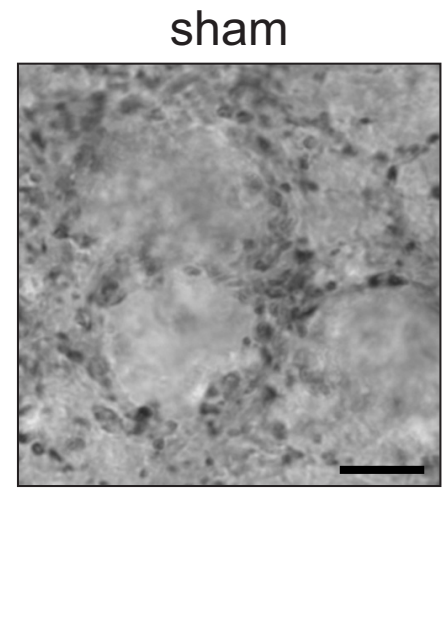

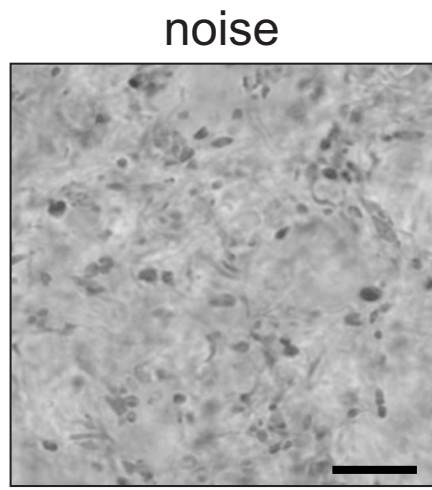

Figure 8. Overall label density in the VCN. A, Quantification of VGLUT1 labeling, calculated as the total number of thresholded pixels divided by the total number of pixels within the entire VCN. Example sections in right panel from a sham-exposed and a noise-exposed individual. Scale bars equal $10 \mu \mathrm{m}$. The overall amount of VGLUT1 expression decreased by $\sim 25 \%$ in noise-exposed mice relative to sham-exposed mice, but this reduction was not statistically significant. $\boldsymbol{B}$, Quantification and examples of GAD65 labeling in sham-exposed and noise-exposed individuals. Noise-exposed animals exhibited a significant reduction of labeling (indicated by asterisk) of $\sim 50 \%$ relative to sham-exposed mice.

exposed mice (Fig. 10B). Accordingly, the interaction between exposure status and frequency was not significant, and post hoc tests indicated noise-exposed mice had significantly less labeling than sham-exposed mice at all frequencies examined (all: $t(8) \geq 3.2, p \leq 0.019, d=0.93$ ). There was also a significant effect of the sex $\times$ frequency interaction (LMM: $\left.F_{(2114)}=3.6, p<0.030, \eta_{p}^{2}=0.06\right)$. As with VGLUT, GAD65 labeling in both sexes decreased as a function of frequency, but the pattern of the sex difference was reversed. Males had more labeling at the lowest frequencies but less labeling at higher frequencies.

\section{Discussion}

Our experiments demonstrate evidence of hyperactivity in the VCN of mice exposed to damaging noise, which appears to result from a widespread loss of inhibition.
While noise-exposed mice had damaged cochleae and elevated ABR thresholds, they showed enhanced reactivity to loud sounds and only slightly elevated behavioral tone detection thresholds. The discrepancy between behavioral and physiologic measures and the imbalance in immunolabeling of excitatory and inhibitory synaptic proteins in the VCN indicate that increased gain in the auditory brainstem can compensate for decreased afferent input to restore or maintain some auditory function.

\section{Neural substrates of hyperactivity}

Noise-exposed mice had elevated ABR wave amplitude ratios compared to sham-exposed mice. Since the late peaks of the ABR are generated by bushy cell-driven pathways (Melcher and Kiang, 1996), elevated wave ratios indicate that these pathways are more responsive than 

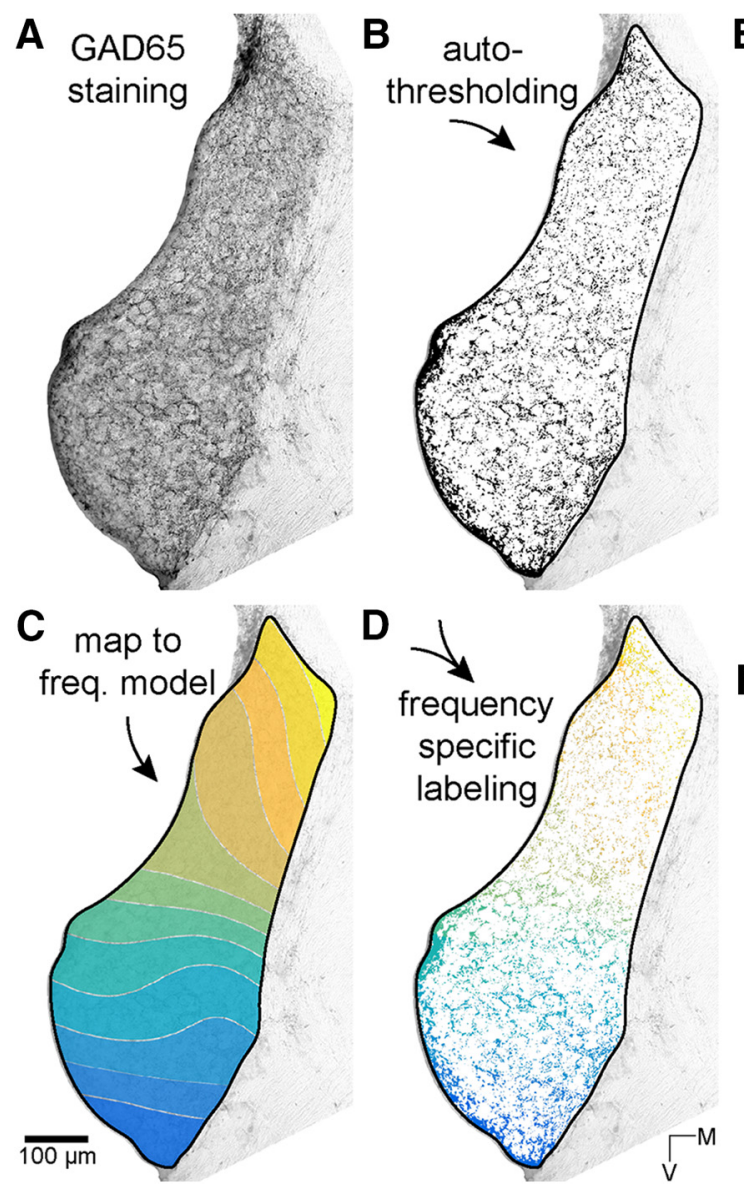

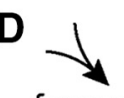

frequit

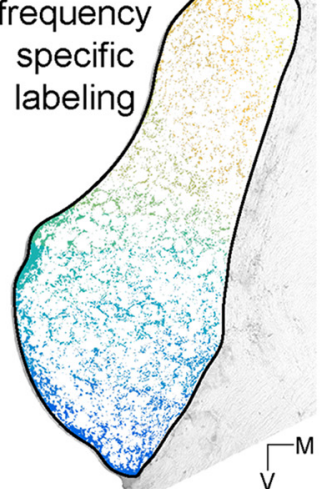

E

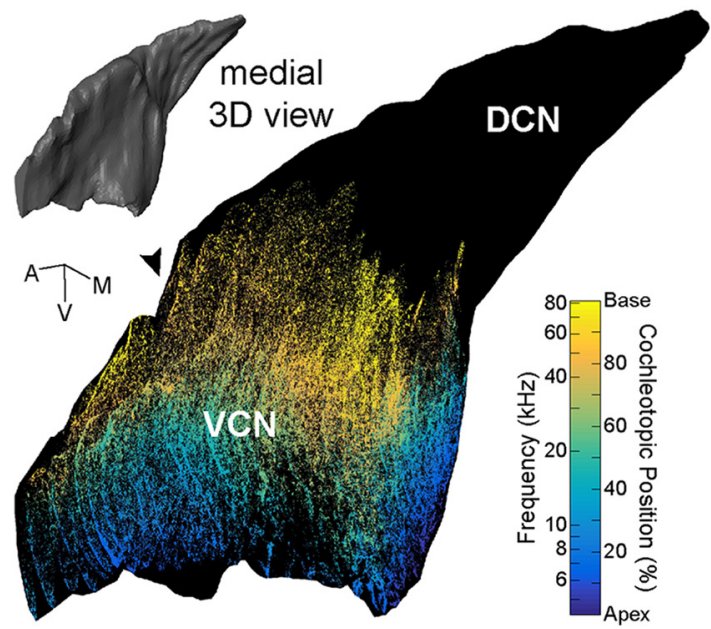

$\mathbf{F}$

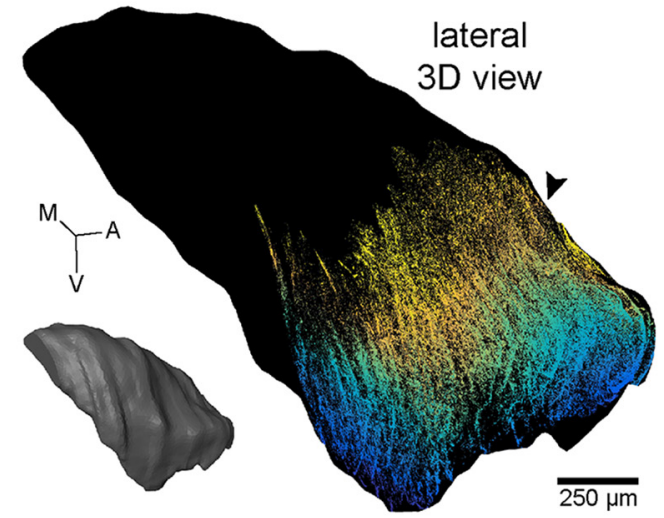

Figure 9. Frequency mapping of immunolabeling. $\boldsymbol{A}$, An example coronal section of the VCN stained for GAD65. $\boldsymbol{B}$, The same section in $\boldsymbol{A}$ following auto-thresholding. Positively-labeled particles are black. The border of the VCN ROI for this section is also shown in black. $\boldsymbol{C}$, The same section in $\boldsymbol{A}$ after its corresponding 3D-reconstructed CN was mapped to the frequency model (Muniak et al., 2013b). Colors indicate assigned frequency values. Contour lines indicate edges of $1 / 4$-octave bins used in subsequent analyses. $\boldsymbol{D}$, Merging of auto-thresholding data $(\boldsymbol{B})$ with frequency mapping $(\boldsymbol{C})$ produces frequency specific GAD65 labeling in the CN. Orientation axes apply to $\boldsymbol{A}-\boldsymbol{D}$. E, 3D reconstruction of frequency-specific GAD65 labeling for a single case. All coronal slices are shown at their corresponding locations within the reconstructed CN. Black arrowhead indicates position of section shown in panels $\boldsymbol{A}-\boldsymbol{D}$. The color gradient is a reflection of the tonotopic organization of the VCN. $\boldsymbol{F}$, Same as in $\boldsymbol{E}$, but shown from a lateral viewpoint.

would be predicted given the decreased peripheral input. We observed hyperactivity mostly at frequencies $>8 \mathrm{kHz}$, corresponding to the frequencies where ABR threshold shifts were largest. While this finding is consistent with the general notion that hyperactivity occurs in the central auditory system after sound exposure, most previous studies have limited their reports to later stages of the ascending auditory pathway and the DCN. However, the VCN, where bushy cells are located, is part of several parallel auditory pathways and is involved in basic sound detection and responsivity (Lauer et al., 2017a), so it is perhaps not surprising that hyperactivity is present already in these pathways. Our finding is consistent with two studies demonstrating enhanced spontaneous and driven activity in VCN following noise exposure (Boettcher and Salvi, 1993; Vogler et al., 2011).

Our anatomic results suggest that hyperactivity in VCN results from an overall loss of inhibition, rather than from large changes in excitation. Noise-exposed mice had significantly less GAD65 labeling than sham-exposed mice across all frequencies, but less VGLUT1 labeling only between $\sim 20$ and $30 \mathrm{kHz}$. The magnitude of the GAD65 decrease coupled with the relative stability of VGLUT1 labeling represents an imbalance between inhibition and excitation in the brainstem that likely accounts for the observed hyperactivity. There was not a strong effect of frequency on any of our results, which is likely due to the broadband character of the exposure. Other authors exposing with different types of noise have found different patterns of hearing loss (Chen et al., 2016).

Our VGLUT1 labeling is consistent with that of Kurioka et al. (2016), who showed that VGLUT1 puncta density decreased in the VCN of noise-exposed mice. Furthermore, studies in a variety of animal models have shown a loss of VGLUT1 in VCN after treatment with ouabain or kanamycin, conductive hearing loss, and mechanical hair cell ablation (Zeng et al., 2009; Fyk-Kolodziej et al., 2011; Yuan et al., 2014; Clarkson et al., 2016). The results of our GAD65 labeling contrasts with that of Zheng et al. (2015), who found no difference in GAD labeling in the VCN of noise-exposed and control rats. However, the rats in the Zheng et al. study did not develop permanent ABR 

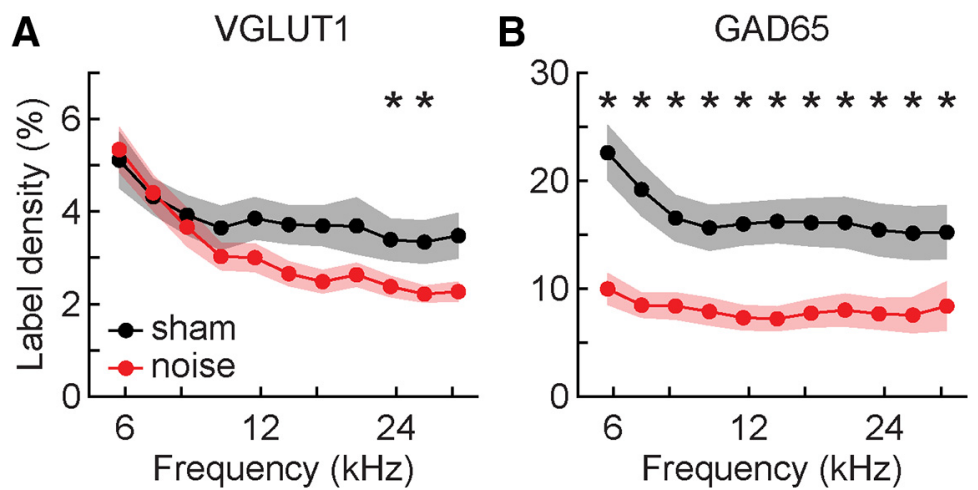

Figure 10. Frequency-specific analysis of immunolabeling. A, Mean density of VGLUT1 expression in the VCN of sham and noise-exposed mice in 1/4-octave bins. B, Mean density of GAD65 expression in the VCN of sham and noise-exposed mice in $1 / 4-o c t a v e$ bins. Asterisks indicate significant differences following post hoc testing.

threshold shifts, probably because of differences in exposure protocol and species-specific susceptibility to noise exposure. Furthermore, Zheng et al. (2015) evaluated GAD expression with an antibody against both GAD65 and GAD67, while the current study targeted only GAD65. The two isoforms tend to localize differently in cells (Soghomonian and Martin, 1998), so it is not surprising that they might be differentially reorganized following sound exposure. It is worth noting that GAD65 in the VCN is likely localized mostly to terminals that co-release glycine and GABA. While glycine is typically considered the primary inhibitory neurotransmitter in the VCN (Wu and Oertel, 1986), GABA predominantly acts to modulate timing (Palombi and Caspary, 1992; Gai and Carney, 2008; Chanda and Xu-Friedman, 2010) and primary inhibition (Lim et al., 2004; Lu et al., 2008; Nerlich et al., 2014). Other forms of peripheral damage are also associated with decreases in inhibitory protein immunolabeling and concentrations of inhibitory amino acid in the VCN (Syka, 2002; Asako et al., 2005; Godfrey et al., 2005, 2008; Lu et al., 2008; Gold and Bajo, 2014).

\section{Central hyperactivity as compensation}

Despite large increases in ABR thresholds, noiseexposed mice did not suffer large behavioral deficits. In fact, noise-exposed mice showed increased reactivity to acoustic startle-inducing stimuli, similar to previous reports (Chen et al., 2013; Salloum et al., 2014). Salloum et al. (2014) showed that increased in ASR reactivity was dependent on a moderate elevation in ABR thresholds, which explains why some other experiments did not identify large differences in the ASR after sound exposure (e.g. Sun et al., 2012; Hickox and Liberman, 2014).

The elevation in ASR amplitudes suggests that soundexposed subjects are sensitized to loud sounds. Soundexposed rats show evidence of increased stress or anxiety (Pace and Zhang, 2013; Lauer et al., 2017b), and emotional states can potentiate the ASR (Davis et al., 1993; Lauer et al., 2017a). Although we did not test for stress, it is possible that the noise-exposed mice in our study experienced negative emotional states a result of the exposure. The exaggerated ASR could additionally be related to the emergence of tinnitus or hyperacusis in our noise-exposed subjects (see Impairments related to cen- tral hyperactivity, below). However, we did not try to determine if any of our animals had either tinnitus or hyperacusis. Regardless of additional factors, the startleeliciting stimulus was sufficient to elicit robust ASRs in noise-exposed mice, providing further support that central gain was able to compensate for reduced peripheral input.

Though ASR measures are informative about reactivity to sounds, they do not necessarily reflect conscious perception, since the animal is not required to attend to the stimuli (Lauer et al., 2017a). In a trained behavioral task, our noiseexposed mice had nearly normal detection thresholds, indicating that perception was not as severely impaired as the ABR thresholds and SGN loss might suggest. These results are consistent with data from aging gerbils, noise-exposed rats, noise-exposed chinchillas, and ouabain-treated mice, in which electrophysiological measures of threshold did not reliably estimate behavioral thresholds after acquired hearing loss (Salvi et al., 1979; Hamann et al., 2002; Heffner et al., 2008; Chambers et al., 2016).

One could argue that ABR thresholds are higher than behavioral thresholds in mice with peripheral trauma because the $A B R$ is a measure of synchronous neural activity and may require coordination of larger numbers of neurons than perception does. However, Ngan and May (2001) showed that ABR thresholds correlate with the thresholds of the single most sensitive auditory nerve fibers in subjects with noise-induced hearing loss, suggesting that the ABR thresholds are not artificially inflated but instead accurately reflect the physiologic status of the auditory nerve after hearing loss.

We suggest that noise-exposed mice preserve or regain some auditory function through compensation in the central auditory system. Several studies have demonstrated increased central gain in response to peripheral damage (Salvi et al., 2003; Gold and Bajo, 2014; Chambers et al., 2016; Clarkson et al., 2016; Möhrle et al., 2016; Zhao et al., 2016), although the underlying mechanisms remain uncertain (Auerbach et al., 2014). This increase in gain is thought to partially compensate for the reduced sensory input. Typically, the compensation is thought to begin in the DCN, inferior colliculus, or auditory cortex. In the present study, we observed hyperactivity in bushy 
cell-driven pathways, suggesting that compensation is already present at the level of the brainstem, at least under the conditions tested here. Mice unilaterally treated with ouabain (Chambers et al., 2016) provide an interesting counterpoint, because when tested only with the treated ear, they show normal behavioral detection thresholds, virtually no ASR, and very little ABR. The mice exhibit hyperactivity at the level of the auditory cortex, with some elevation in the inferior colliculus. Ouabain eliminates nearly all type I SGNs and their central processes (Lang et al., 2005), but other forms of peripheral damage usually spare most SGNs and their central processes (Zilberstein et al., 2012; McGuire et al., 2015). This difference in SGN survival likely accounts for the lack of startle response in the ouabain-treated animals and may explain why compensation is strongest at the level of the cortex. Nevertheless, our experiments demonstrate that gain compensation is possible at the first level of the central auditory pathway.

\section{Impairments related to central hyperactivity}

Central hyperactivity may be able to compensate for the loss of afferent input from the ear, and thus may represent a potential target for novel treatments. However, it has also been associated with various forms of hearing dysfunction. Increased central ABR wave amplitudes relative to wave 1 have been implicated in tinnitus and reduced sound tolerance in some human studies (Attias et al., 2005; Gu et al., 2010; Schaette and McAlpine, 2011), although not in others (Møller et al., 1992; Gilles et al., 2016). In animal studies, central hyperactivity has been associated with tinnitus, reduced sound tolerance, and loudness recruitment (Attias et al., 2005; Cai et al., 2009; Middleton et al., 2011; Heeringa and van Dijk, 2014; Kalappa et al., 2014). Tinnitus and reduced sound tolerance are associated with impaired speech comprehension in noise (Vielsmeier et al., 2016) and can cause difficulty using amplification devices (Lindley et al., 2001; Formby et al., 2008). Hyperactivity in central auditory pathways could affect other aspects of perception such as spectral contrast perception and temporal processing (Møller, 1972; Blackburn and Sachs, 1990; Young et al., 1992; Doucet et al., 1999; McGinley and Oertel, 2006; Chen et al., 2016). Central hyperactivity may also result in abnormal activation of the olivocochlear pathways (Knudson et al., 2014; Dragicevic et al., 2015), which could further reduce the afferent input to the brain and affect hearing in noise and selective attention (Delano et al., 2007; Sturm and Weisz, 2015). Thus, while detection of sounds may be restored by central hyperactivity, more complex aspects of hearing may be adversely affected. While we did not test our subjects for tinnitus or sound tolerance, some subset of our subjects may have experienced one or more of these additional pathologies. Identification of these subgroups in future studies (following, e.g., Gu et al., 2010; Hickox and Liberman, 2014) may reduce variability in results and inform our understanding of these pathologies. When developing therapies and optimizing prosthetic devices, it is important to consider how the central auditory system may compensate for peripheral changes.

\section{References}

Asako M, Holt AG, Griffith RD, Buras ED, Altschuler RA (2005) Deafness-related decreases in glycine-immunoreactive labeling in the rat cochlear nucleus. J Neurosci Res 81:102-109. CrossRef Medline

Attias J, Zwecker-Lazar I, Nageris B, Keren O, Groswasser Z (2005) Dysfunction of the auditory efferent system in patients with traumatic brain injuries with tinnitus and hyperacusis. J Basic Clin Physiol Pharmacol 16:117-126. Medline

Auerbach BD, Rodrigues PV, Salvi RJ (2014) Central gain control in tinnitus and hyperacusis. Front Neurol 5:206. CrossRef Medline

Barker M, Solinski HJ, Hashimoto H, Tagoe T, Pilati N, Hamann M (2012) Acoustic overexposure increases the expression of VGLUT-2 mediated projections from the lateral vestibular nucleus to the dorsal cochlear nucleus. PLoS One 7:e35955. CrossRef Medline

Bauer CA, Turner JG, Caspary DM, Myers KS, Brozoski TJ (2008) Tinnitus and inferior colliculus activity in chinchillas related to three distinct patterns of cochlear trauma. J Neurosci Res 86:25642578. CrossRef Medline

Blackburn CC, Sachs MB (1990) The representations of the steadystate vowel sound/e/in the discharge patterns of cat anteroventral cochlear nucleus neurons. J Neurophysiol 63:1191-1212. CrossRef

Boettcher FA, Salvi RJ (1993) Functional changes in the ventral cochlear nucleus following acute acoustic overstimulation. J Acoust Soc Am 94:2123-2134. Medline

Brozoski TJ, Bauer CA, Caspary DM (2002) Elevated fusiform cell activity in the dorsal cochlear nucleus of chinchillas with psychophysical evidence of tinnitus. J Neurosci 22:2383-2390. Medline

Brozoski TJ, Ciobanu L, Bauer CA (2007) Central neural activity in rats with tinnitus evaluated with manganese-enhanced magnetic resonance imaging (MEMRI). Hear Res 228:168-179. CrossRef Medline

Cai S, Ma W-LD, Young ED (2009) Encoding intensity in ventral cochlear nucleus following acoustic trauma: implications for loudness recruitment. J Assoc Res Otolaryngol 10:5-22. CrossRef Medline

Cardona A, Saalfeld S, Schindelin J, Arganda-Carreras I, Preibisch S, Longair M, Tomancak P, Hartenstein V, Douglas RJ (2012) TrakEM2 software for neural circuit reconstruction. PLoS One 7:e38011. CrossRef Medline

Chambers AR, Resnik J, Yuan Y, Whitton JP, Edge AS, Liberman MC, Polley DB (2016) Central gain restores auditory processing following near-complete cochlear denervation. Neuron 89:867879. CrossRef Medline

Chanda S, Xu-Friedman MA (2010) Neuromodulation by GABA converts a relay into a coincidence detector. J Neurophysiol 104: 2063-2074. CrossRef Medline

Chen G, Lee C, Sandridge SA, Butler HM, Manzoor NF, Kaltenbach JA (2013) Behavioral evidence for possible simultaneous induction of hyperacusis and tinnitus following intense sound exposure. $J$ Assoc Res Otolaryngol 14:413-424. CrossRef Medline

Chen G-D, Sheppard A, Salvi R (2016) Noise trauma induced plastic changes in brain regions outside the classical auditory pathway. Neuroscience 315:228-245. CrossRef Medline

Clarkson C, Antunes FM, Rubio ME (2016) Conductive hearing loss has long-lasting structural and molecular effects on presynaptic and postsynaptic structures of auditory nerve synapses in the cochlear nucleus. J Neurosci 36:10214-10227. CrossRef Medline

Cohen J (1973) Eta-squared and partial eta-squared in fixed factor anova designs. Educ Psychol Meas 33:107-112. CrossRef

Connelly CJ, Ryugo DK, Muniak MA (2017) The effect of progressive hearing loss on the morphology of endbulbs of Held and bushy cells. Hear Res 343:14-33. CrossRef Medline 
Davis M, Falls WA, Campeau S, Kim M (1993) Fear-potentiated startle: a neural and pharmacological analysis. Behav Brain Res 58:175-198. Medline

Dehmel S, Eisinger DS, Shore S (2012a) Gap prepulse inhibition and auditory brainstem-evoked potentials as objective measures for tinnitus in guinea pigs. Front Syst Neurosci 6:42. CrossRef

Dehmel S, Pradhan S, Koehler S, Bledsoe S, Shore S (2012b) Noise overexposure alters long-term somatosensory-auditory processing in the dorsal cochlear nucleus-possible basis for tinnitusrelated hyperactivity? J Neurosci 32:1660-1671. CrossRef

Delano PH, Elgueda D, Hamame CM, Robles L (2007) Selective attention to visual stimuli reduces cochlear sensitivity in chinchillas. J Neurosci 27:4146-4153. CrossRef Medline

Dong S, Mulders WHAM, Rodger J, Woo S, Robertson D (2010) Acoustic trauma evokes hyperactivity and changes in gene expression in guinea-pig auditory brainstem. Eur $\mathrm{J}$ Neurosci 31: 1616-1628. CrossRef Medline

Doucet JR, Ross AT, Gillespie MB, Ryugo DK (1999) Glycine immunoreactivity of multipolar neurons in the ventral cochlear nucleus which project to the dorsal cochlear nucleus. J Comp Neur 408: 515-531. Medline

Dragicevic CD, Aedo C, León A, Bowen M, Jara N, Terreros G, Robles L, Delano PH (2015) The olivocochlear reflex strength and cochlear sensitivity are independently modulated by auditory cortex microstimulation. J Assoc Res Otolaryngol 16:223-240. CrossRef Medline

Feldblum S, Erlander MG, Tobin AJ (1993) Different distributions of GAD65 and GAD67 mRNAS suggest that the two glutamate decarboxylases play distinctive functional roles. J Neurosci Res 34: 689-706. CrossRef

Formby C, Hawley M, Sherlock L, Gold S, Segar A, Gmitter C, Cannavo J (2008) Intervention for restricted dynamic range and reduced sound tolerance. J Acoust Soc Am 123:3717-3717. CrossRef

Fyk-Kolodziej B, Shimano T, Gong T-W, Holt AG (2011) Vesicular glutamate transporters: spatio-temporal plasticity following hearing loss. Neuroscience 178:218-239. CrossRef Medline

Gai Y, Carney LH (2008) Influence of inhibitory inputs on rate and timing of responses in the anteroventral cochlear nucleus. J Neurophysiol 99:1077-1095. CrossRef Medline

Gilles A, Schlee W, Rabau S, Wouters K, Fransen E, Van de Heyning $P$ (2016) Decreased speech-in-noise understanding in young adults with tinnitus. Front Neurosci 10:288. CrossRef Medline

Godfrey DA, Chen K, Godfrey MA, Jin Y-M, Robinson KT, Hair C (2008) Effects of cochlear ablation on amino acid concentrations in the chinchilla posteroventral cochlear nucleus, as compared to rat. Neuroscience 154:304-314. CrossRef Medline

Godfrey DA, Godfrey MA, Ding D-L, Chen K, Salvi RJ (2005) Amino acid concentrations in chinchilla cochlear nucleus at different times after carboplatin treatment. Hear Res 206:64-73. CrossRef Medline

Gold JR, Bajo VM (2014) Insult-induced adaptive plasticity of the auditory system. Front Neurosci 8:110. CrossRef Medline

Gómez-Nieto R, Rubio ME (2009) A bushy cell network in the rat ventral cochlear nucleus. J Comp Neur 516:241-263. CrossRef Medline

Gravel JS, Ruben RJ (1996) Auditory deprivation and its consequences: from animal models to humans. In: Clinical Aspects of Hearing (Water TRVD, Popper AN, Fay RR, eds), pp 86-115. Springer Handbook of Auditory Research. Springer, New York.

Gu JW, Halpin CF, Nam E-C, Levine RA, Melcher JR (2010) Tinnitus, diminished sound-level tolerance, and elevated auditory activity in humans with clinically normal hearing sensitivity. J Neurophysiol 104:3361-3370. CrossRef Medline

Hamann I, Gleich O, Klump GM, Kittel MC, Boettcher FA, Schmiedt RA, Strutz J (2002) Behavioral and evoked-potential thresholds in young and old Mongolian gerbils (Meriones unguiculatus). Hear Res 171:82-95. CrossRef

Heeringa AN, van Dijk P (2014) The dissimilar time course of temporary threshold shifts and reduction of inhibition in the inferior colliculus following intense sound exposure. Hear Res 312:38-47. CrossRef Medline

Heffner HE, Koay G, Heffner RS (2006) Behavioral assessment of hearing in mice-conditioned suppression. Current protocols in neuroscience 34:8-21. Medline

Heffner HE, Koay G, Heffner RS (2008) Comparison of behavioral and auditory brainstem response measures of threshold shift in rats exposed to loud sound. J Acoust Soc Am 124:1093-1104. CrossRef Medline

Henderson D, Bielefeld EC, Harris KC, Hu B-H (2006) The role of oxidative stress in noise-induced hearing loss. Ear Hear 27:1-19. CrossRef Medline

Hequembourg S, Liberman MC (2001) Spiral ligament pathology: a major aspect of age-related cochlear degeneration in C57BL/6 mice. J Assoc Res Otolaryngol 2:118-129. CrossRef

Hickox AE, Liberman MC (2014) Is noise-induced cochlear neuropathy key to the generation of hyperacusis or tinnitus?. J Neurophysiol 111:552-564. CrossRef Medline

Izquierdo MA, Gutiérrez-Conde PM, Merchán MA, Malmierca MS (2008) Non-plastic reorganization of frequency coding in the inferior colliculus of the rat following noise-induced hearing loss. Neuroscience 154:355-369. CrossRef Medline

Juiz JM, Helfert RH, Bonneau JM, Wenthold RJ, Altschuler RA (1996) Three classes of inhibitory amino acid terminals in the cochlear nucleus of the guinea pig. J Comp Neur 373:11-26. CrossRef Medline

Kalappa BI, Brozoski TJ, Turner JG, Caspary DM (2014) Single unit hyperactivity and bursting in the auditory thalamus of awake rats directly correlates with behavioural evidence of tinnitus. J Physiol 592:5065-5078. CrossRef Medline

Kaltenbach JA (2007) The dorsal cochlear nucleus as a contributor to tinnitus: mechanisms underlying the induction of hyperactivity. In: Progress in Brain Research (B Langguth, GHT Kleinjung, A Cacace and AR Møller, ed), pp 89-106 Tinnitus: Pathophysiology and Treatment. Elsevier.

Kaltenbach JA, Zhang J, Afman CE (2000) Plasticity of spontaneous neural activity in the dorsal cochlear nucleus after intense sound exposure. Hear Res 147:282-292. Medline

Knudson IM, Shera CA, Melcher JR (2014) Increased contralateral suppression of otoacoustic emissions indicates a hyperresponsive medial olivocochlear system in humans with tinnitus and hyperacusis. J Neurophysiol 112:3197-3208. CrossRef Medline

Kurioka T, Lee MY, Heeringa AN, Beyer LA, Swiderski DL, Kanicki AC, Kabara LL, Dolan DF, Shore SE, Raphael Y (2016) Selective hair cell ablation and noise exposure lead to different patterns of changes in the cochlea and the cochlear nucleus. Neuroscience 332:242-257. CrossRef Medline

Lang H, Schulte BA, Schmiedt RA (2005) Ouabain induces apoptotic cell death in type I spiral ganglion neurons, but not type II neurons. $\mathrm{J}$ Assoc Res Otolaryngol 6:63-74. CrossRef Medline

Lauer AM, May BJ, Hao ZJ, Watson J (2009) Analysis of environmental sound levels in modern rodent housing rooms. Lab animal 38:154-160. CrossRef

Lauer AM, Slee SJ, May BJ (2011) Acoustic basis of directional acuity in laboratory mice. Journal of the Association for Research in Otolaryngology 12:633-645.

Lauer AM (2017) Minimal effects of age and exposure to a noisy environment on hearing in alpha9 nicotinic receptor knockout mice. Front Neurosci 11:304. CrossRef Medline

Lauer AM, Behrens D, Klump G (2017a) Acoustic startle modification as a tool for evaluating auditory function of the mouse: progress, pitfalls, and potential. Neurosci Biobehav Rev 77:194-208. CrossRef

Lauer AM, Connelly CJ, Graham H, Ryugo DK (2013) Morphological characterization of bushy cells and their inputs in the laboratory mouse (Mus musculus) anteroventral cochlear nucleus. PLoS One 8:e73308. CrossRef

Lauer AM, Larkin G, Jones A, May BJ (2017b) Behavioral animal model of the emotional response to tinnitus and hearing loss. $J$ Assoc Res Otolaryngol 1-15. 
Lefcheck JS (2016) piecewiseSEM: piecewise structural equation modelling in R for ecology, evolution, and systematics. Methods Ecol Evol 7:573-579. CrossRef

Lim R, Alvarez FJ, Walmsley B (2004) GABA mediates presynaptic inhibition at glycinergic synapses in a rat auditory brainstem nucleus. J Physiol 525:447-459. CrossRef

Lindley GA, Palmer CV, Durrant J, Pratt S (2001) Audiologist- versus patient-driven hearing aid fitting protocols. Semin Hear 22:139160. CrossRef

Longenecker RJ, Galazyuk AV (2011) Development of tinnitus in CBA/CaJ mice following sound exposure. J Assoc Res Otolaryngol 12:647. CrossRef Medline

Lowe AS, Walton JP (2015) Alterations in peripheral and central components of the auditory brainstem response: a neural assay of tinnitus. PLoS One 10:e0117228. CrossRef Medline

Lu T, Rubio ME, Trussell LO (2008) Glycinergic transmission shaped by the corelease of GABA in a mammalian auditory synapse. Neuron 57:524-535. CrossRef

Ma W-LD, Hidaka H, May BJ (2006) Spontaneous activity in the inferior colliculus of $\mathrm{CBA} / \mathrm{J}$ mice after manipulations that induce tinnitus. Hear Res 212:9-21. CrossRef Medline

McGinley MJ, Oertel D (2006) Rate thresholds determine the precision of temporal integration in principal cells of the ventral cochlear nucleus. Hear Res 216-217:52-63. CrossRef Medline

McGuire B, Fiorillo B, Ryugo DK, Lauer AM (2015) Auditory nerve synapses persist in ventral cochlear nucleus long after loss of acoustic input in mice with early-onset progressive hearing loss. Brain Res 1605:22-30. CrossRef Medline

Melcher JR, Kiang NYS (1996) Generators of the brainstem auditory evoked potential in cat III: identified cell populations. Hear Res 93:52-71. CrossRef

Middleton JW, Kiritani T, Pedersen C, Turner JG, Shepherd GMG, Tzounopoulos T (2011) Mice with behavioral evidence of tinnitus exhibit dorsal cochlear nucleus hyperactivity because of decreased GABAergic inhibition. Proc Natl Acad Sci U S A 108:76017606. CrossRef

Milbrandt JC, Holder TM, Wilson MC, Salvi RJ, Caspary DM (2000) GAD levels and muscimol binding in rat inferior colliculus following acoustic trauma. Hear Res 147:251-260. Medline

Möhrle D, Ni K, Varakina K, Bing D, Lee SC, Zimmermann U, Knipper $M$, Rüttiger $L$ (2016) Loss of auditory sensitivity from inner hair cell synaptopathy can be centrally compensated in the young but not old brain. Neurobiol Aging 44:173-184. CrossRef

Møller AR (1972) Coding of amplitude and frequency modulated sounds in the cochlear nucleus of the rat. Acta Physiol Scand 86:223-238. CrossRef

Møller AR, Møller MB, Yokota M (1992) Some forms of tinnitus may involve the extralemniscal auditory pathway. Laryngoscope 102: 1165-1171. CrossRef Medline

Muly SM, Gross JS, Potashner SJ (2004) Noise trauma alters $\mathrm{D}-[3 \mathrm{H}]$ aspartate release and AMPA binding in chinchilla cochlear nucleus. J Neurosci Res 75:585-596. CrossRef

Muniak MA, Connelly CJ, Tirko NN, O'Neil JN, Ryugo DK (2013a) Synaptic organization and plasticity in the auditory system of the deaf white cat. In: Deafness (Kral A, Popper AN, Fay RR, eds), pp 83-128. New York: Springer.

Muniak MA, Rivas A, Montey KL, May BJ, Francis HW, Ryugo DK (2013b) 3D model of frequency representation in the cochlear nucleus of the CBA/J mouse. J Comp Neur 521:1510-1532. CrossRef

Nakagawa S, Johnson PCD, Schielzeth H (2017) The coefficient of determination R2 and intra-class correlation coefficient from generalized linear mixed-effects models revisited and expanded. J R Soc Interface 14:20170213.

Nerlich J, Kuenzel T, Keine C, Korenic A, Rübsamen R, Milenkovic I (2014) Dynamic fidelity control to the central auditory system: synergistic glycine/GABAergic inhibition in the cochlear nucleus. $J$ Neurosci 34:11604-11620. CrossRef Medline
Ngan EM, May BJ (2001) Relationship between the auditory brainstem response and auditory nerve thresholds in cats with hearing loss. Hear Res 156:44-52. Medline

Obata K, Hirono M, Kume N, Kawaguchi Y, Itohara S, Yanagawa Y (2008) GABA and synaptic inhibition of mouse cerebellum lacking glutamate decarboxylase 67. Biochem Biophys Res Commun 370: 429-433. CrossRef Medline

Overbeck GW, Church MW (1992) Effects of tone burst frequency and intensity on the auditory brainstem response (ABR) from albino and pigmented rats. Hear Res 59:129-137. Medline

Pace E, Zhang J (2013) Noise-induced tinnitus using individualized gap detection analysis and its relationship with hyperacusis, anxiety, and spatial cognition. PLoS One 8:e75011. CrossRef Medline

Palombi PS, Caspary DM (1992) GABAA receptor antagonist bicuculline alters response properties of posteroventral cochlear nucleus neurons. J Neurophysiol 67:738-746. CrossRef Medline

Potashner SJ, Suneja SK, Benson CG (1997) Regulation of $\mathrm{d}$-aspartate release and uptake in adult brain stem auditory nuclei after unilateral middle ear ossicle removal and cochlear ablation. Exp Neurol 148:222-235. CrossRef

R Development Core Team (2017) R: a language and environment for statistical computing. R Found Stat Comput. Available at: URL http://www.R-project.org/.

Richardson JTE (2011) Eta squared and partial eta squared as measures of effect size in educational research. Educ Res Rev 6:135-147. CrossRef

Rico B, Xu B, Reichardt LF (2002) TrkB receptor signaling is required for establishment of GABAergic synapses in the cerebellum. Nat Neurosci 5:225-233. CrossRef Medline

Robertson D, Bester C, Vogler D, Mulders WHAM (2013) Spontaneous hyperactivity in the auditory midbrain: relationship to afferent input. Hear Res 295:124-129. CrossRef

Saalfeld S, Cardona A, Hartenstein V, Tomančák P (2010) As-rigidas-possible mosaicking and serial section registration of large ssTEM datasets. Bioinformatics 26:i57-i63. CrossRef

Salloum RH, Yurosko C, Santiago L, Sandridge SA, Kaltenbach JA (2014) Induction of enhanced acoustic startle response by noise exposure: dependence on exposure conditions and testing parameters and possible relevance to hyperacusis. PLoS One 9:e111747. CrossRef Medline

Salvi RJ, Ding D, Wang J, McFadden SL, Sun W (2003) Functional changes in peripheral and central auditory pathways following selective inner hair cell loss. Semin Hear 24:135-146. CrossRef

Salvi RJ, Hamernik RP, Henderson D (1979) Auditory nerve activity and cochlear morphology after noise exposure. Arch Otorhinolaryngol 224:111-116. Medline

Salvi RJ, Wang J, Ding D (2000) Auditory plasticity and hyperactivity following cochlear damage. Hear Res 147:261-274. Medline

Saunders JC, Dear SP, Schneider ME (1985) The anatomical consequences of acoustic injury: a review and tutorial. J Acoust Soc Am 78:833-860. Medline

Schaette R, McAlpine D (2011) Tinnitus with a normal audiogram: physiological evidence for hidden hearing loss and computational model. J Neurosci 31:13452-13457. CrossRef

Schettino AE, Lauer AM (2013) The efficiency of design-based stereology in estimating spiral ganglion populations in mice. Hearing research 304:153-158. CrossRef

Schindelin J, Arganda-Carreras I, Frise E, Kaynig V, Longair M, Pietzsch T, Preibisch S, Rueden C, Saalfeld S, Schmid B, Tinevez J-Y, White DJ, Hartenstein V, Eliceiri K, Tomancak P, Cardona A (2012) Fiji: an open-source platform for biological-image analysis. Nat Methods 9:676. CrossRef Medline

Schmiedt RA (1984) Acoustic injury and the physiology of hearing. J Acoust Soc Am 76:1293-1317. Medline

Seki S, Eggermont JJ (2003) Changes in spontaneous firing rate and neural synchrony in cat primary auditory cortex after localized tone-induced hearing loss. Hear Res 180:28-38. Medline

Shepherd RK, Meltzer NE, Fallon JB, Ryugo DK (2006) Consequences of deafness and electrical stimulation on the peripheral and central auditory system. In: Cochlear Implants, 2nd ed. (Waltz- 
man SB, Roland JT, Jr, eds), pp 25-39. New York: Thieme Medial Publishers.

Shore SE, Koehler S, Oldakowski M, Hughes LF, Syed S (2008) Dorsal cochlear nucleus responses to somatosensory stimulation are enhanced after noise-induced hearing loss. Eur $\mathrm{J}$ Neurosci 27:155-168. CrossRef Medline

Soghomonian J-J, Martin DL (1998) Two isoforms of glutamate decarboxylase: why? Trends Pharmacol Sci 19:500-505. Medline

Sturm JJ, Weisz CJC (2015) Hyperactivity in the medial olivocochlear efferent system is a common feature of tinnitus and hyperacusis in humans. J Neurophysiol 114:2551-2554. CrossRef Medline

Sun W, Deng A, Jayaram A, Gibson B (2012) Noise exposure enhances auditory cortex responses related to hyperacusis behavior. Brain Res 1485:108-116. CrossRef Medline

Syka J (2002) Plastic changes in the central auditory system after hearing loss, restoration of function, and during learning. Physiol Rev 82:601-636. CrossRef Medline

Vielsmeier V, Kreuzer PM, Haubner F, Steffens T, Semmler PRO, Kleinjung T, Schlee W, Langguth B, Schecklmann M (2016) Speech comprehension difficulties in chronic tinnitus and its relation to hyperacusis. Front Aging Neurosci 8:293. CrossRef

Vogler DP, Robertson D, Mulders WHAM (2011) Hyperactivity in the ventral cochlear nucleus after cochlear trauma. J Neurosci 31: 6639-6645. CrossRef Medline

Willard FH, Ryugo DK (1983) Anatomy of the central auditory system. In: The Auditory Psychobiology of the Mouse (Willott JF, ed), pp 201-304. Springfield, IL: Charles C Thomas.

Wu SH, Oertel D (1986) Inhibitory circuitry in the ventral cochlear nucleus is probably mediated by glycine. J Neurosci 6:2691-2706. Medline
Young ED, Spirou GA, Rice JJ, Voigt HF, Rees A (1992) Neural organization and responses to complex stimuli in the dorsal cochlear nucleus [and discussion]. Philos Trans R Soc B Biol Sci 336:407-413. CrossRef

Yuan Y, Shi F, Yin Y, Tong M, Lang H, Polley DB, Liberman MC, Edge ASB (2014) Ouabain-induced cochlear nerve degeneration: synaptic loss and plasticity in a mouse model of auditory neuropathy. J Assoc Res Otolaryngol 15:31-43. CrossRef

Zeng C, Nannapaneni N, Zhou J, Hughes LF, Shore S (2009) Cochlear damage changes the distribution of vesicular glutamate transporters associated with auditory and nonauditory inputs to the cochlear nucleus. J Neurosci 29:4210-4217. CrossRef Medline

Zhao Y, Song Q, Li X, Li C (2016) Neural hyperactivity of the central auditory system in response to peripheral damage. Neural Plast 2016:2162105. CrossRef Medline

Zheng QY, Johnson KR, Erway LC (1999) Assessment of hearing in 80 inbred strains of mice by ABR threshold analyses. Hear Res 130:94-107. Medline

Zheng Y, Dixon S, MacPherson K, Smith PF (2015) Glutamic acid decarboxylase levels in the cochlear nucleus of rats with acoustic trauma-induced chronic tinnitus. Neurosci Lett 586:60-64. CrossRef Medline

Zhou X, Jen PH-S, Seburn KL, Frankel WN, Zheng QY (2006) Auditory brainstem responses in 10 inbred strains of mice. Brain Res 1091:16-26. CrossRef Medline

Zilberstein Y, Liberman MC, Corfas G (2012) Inner hair cells are not required for survival of spiral ganglion neurons in the adult cochlea. J Neurosci 32:405-410. CrossRef Medline 